\title{
Bicarbonate correction of ketoacidosis alters host- pathogen interactions and alleviates mucormycosis
}

\author{
Teclegiorgis Gebremariam, ${ }^{1,2}$ Lin Lin, ${ }^{1,2}$ Mingfu Liu, ${ }^{1,2}$ Dimitrios P. Kontoyiannis, ${ }^{3}$ Samuel French,,${ }^{2,4}$ John E. Edwards Jr., ${ }^{1,2,4}$ \\ Scott G. Filler, ${ }^{1,2,4}$ and Ashraf S. Ibrahim ${ }^{1,2,4}$ \\ 'Division of Infectious Diseases and 'Los Angeles Biomedical Research Institute, Harbor-University of California, Los Angeles (UCLA) Medical Center, Torrance, California, USA. ${ }^{3}$ Department of Infectious \\ Diseases, Infection Control and Employee Health, The University of Texas MD Anderson Cancer Center, Houston, Texas, USA. ${ }^{4}$ David Geffen School of Medicine, UCLA, Los Angeles, California, USA.
}

\begin{abstract}
Patients with diabetic ketoacidosis (DKA) are uniquely predisposed to mucormycosis, an angioinvasive fungal infection with high mortality. Previously, we demonstrated that Rhizopus invades the endothelium via binding of fungal CotH proteins to the host receptor GRP78. Here, we report that surface expression of GRP78 is increased in endothelial cells exposed to physiological concentrations of $\beta$-hydroxy butyrate (BHB), glucose, and iron that are similar to those found in DKA patients. Additionally, expression of $R$. oryzae CotH was increased within hours of incubation with DKA-associated concentrations of $\mathrm{BHB}$, glucose, and iron, augmenting the ability of $R$. oryzae to invade and subsequently damage endothelial cells in vitro. BHB exposure also increased fungal growth and attenuated $R$. oryzae neutrophil-mediated damage. Further, mice given BHB developed clinical acidosis and became extremely susceptible to mucormycosis, but not aspergillosis, while sodium bicarbonate reversed this susceptibility. BHB-related acidosis exerted a direct effect on both GRP78 and CotH expression, an effect not seen with lactic acidosis. However, BHB also indirectly compromised the ability of transferrin to chelate iron, as iron chelation combined with sodium bicarbonate completely protected endothelial cells from $R$ hizopus-mediated invasion and damage. Our results dissect the pathogenesis of mucormycosis during ketoacidosis and reinforce the importance of careful metabolic control of the acidosis to prevent and manage this infection.
\end{abstract}

\section{Introduction}

Mucormycosis is a severe, frequently fatal fungal infection that has a unique predisposition to infect patients with diabetic ketoacidosis (DKA) $(1,2)$. It is also seen in the settings of severe trauma and immunosuppression due to neutropenia, corticosteroid treatment, or organ transplantation $(1,2)$. The infection is caused by organisms belonging to the order Mucorales, among which Rhizopus species are the most common cause of the disease $(1,2)$.

Despite current treatment options, which often include extensive surgery and antifungal therapy, the overall mortality of mucormycosis remains higher than $40 \%$, and approaches $100 \%$ in patients with hematogenously disseminated disease, prolonged neutropenia, and brain involvement $(1,2)$.

A hallmark of mucormycosis is the ability of the causative agent to invade blood vessels that results in rapidly progressive infection $(1,2)$. Therefore, interactions of Mucorales with the endothelial cell lining of the blood vessels represent a critical step in the pathogenesis of mucormycosis. We have shown that Mucorales adhere to and invade endothelial cells (3) by expressing CotH proteins (4). CotH proteins bind to the heat shock host receptor glucose-regulated protein 78 (GRP78) (5), causing host cells to endocytose the organisms. We also found that elevated concentrations of glucose and iron, comparable to those seen during hyperglycemia and DKA, enhance GRP78 expression, leading to enhanced fungal invasion and damage of endothelial cells (5). Consistent with in vitro data,

Conflict of interest: The authors have declared that no conflict of interest exists. Submitted: May 11, 2015; Accepted: March 22, 2016.

Reference information: J Clin Invest. 2016;126(6):2280-2294. doi:10.1172/JCI82744. mice with DKA were found to express more GRP78 in the target organs than normal mice and were protected from mucormycosis when given anti-GRP78 antibodies (5).

Here, to understand the unique susceptibility of patients with DKA to mucormycosis, we investigated the effects of $\beta$-hydroxy butyrate-induced (BHB-induced) acidosis on both the host and the fungus. We hypothesized that hyperglycemia and its complication of ketoacidosis release iron from iron-binding proteins, which in turn triggers the overexpression of $\mathrm{R}$. oryzae CotH proteins and their mammalian GRP78 receptor, leading to a cascade of events that enable $R$. oryzae to proliferate and invade the host. We found BHB to enhance growth of $R$. oryzae and suppress neutrophil-mediated killing of the fungus. While application of $\mathrm{BHB}$ to immunocompetent mice induced clinical acidosis that resulted in release of iron from plasma iron-sequestering proteins, a direct effect of BHB to enhance simultaneously the cell surface expression of the host GRP78 and fungal CotH proteins is detected with resultant enhanced severity of mucormycosis in vitro and in vivo. Further, acidosis due to lactic acid did not alter the expression of GRP78 or CotH3, suggesting that the effect of $\mathrm{BHB}$ on the host receptor and fungal ligand is specific. Our finding that sodium bicarbonate $\left(\mathrm{NaHCO}_{3}\right)$ reversed the pleotropic effect of $\mathrm{BHB}$ in vitro and protected $\mathrm{BHB}$-treated mice from mucormycosis is of clinical importance.

Our data provide an explanation for the increased susceptibility of DKA, but not lactic acidosis, patients to mucormycosis and emphasize the critical role of $\mathrm{pH}$ homeostasis, iron, and glucose in the pathogenesis of this lethal infection. While patients with DKA do not routinely have their acidosis corrected with bicarbonate 
A

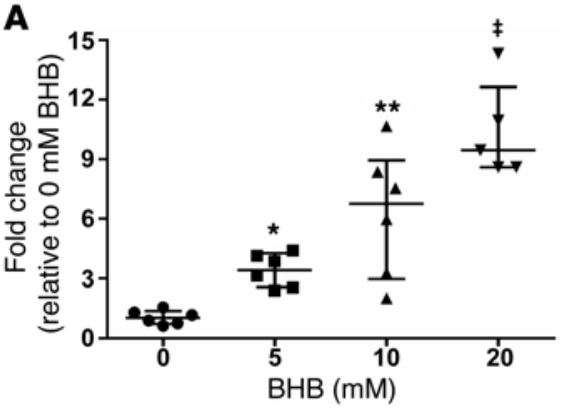

B

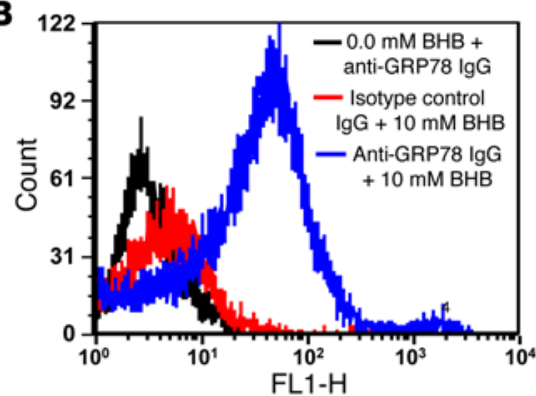

C

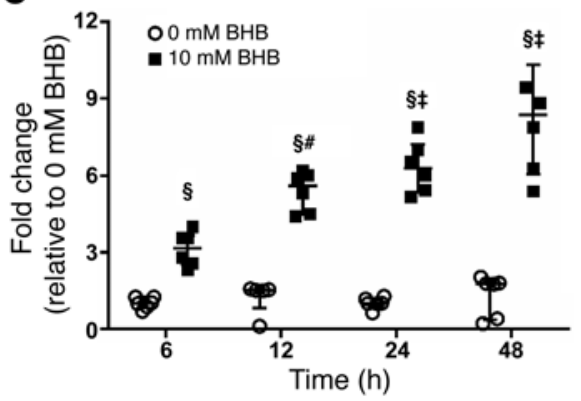

D

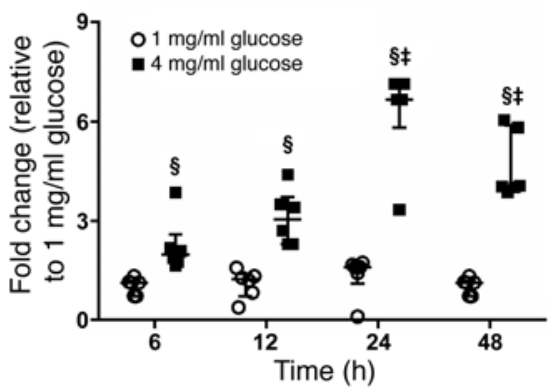

E

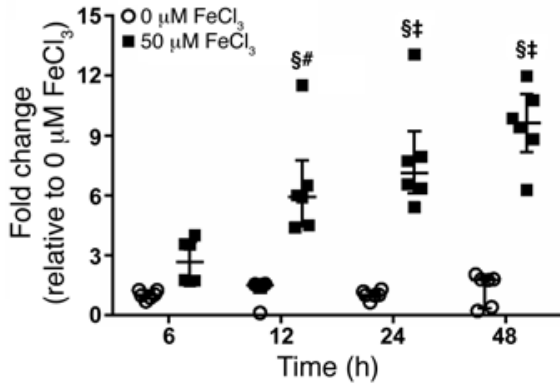

Figure 1. BHB, glucose, and iron concentrations consistent with those seen in DKA patients induce expression of GRP78 in a time- and concentrationdependent manner. (A) Endothelial cells were incubated with varying concentrations of BHB for 24 hours before quantification of the expression of host GRP78 by real-time RT-PCR (normalized to GADPH housekeeping gene). (B) Flow cytometry testing using anti-GRP78 antibodies demonstrated enhanced cell surface expression of GRP78 protein on endothelial cells exposed to $10 \mathrm{mM}$ BHB compared with endothelial cells without exposure to BHB. Cell surface staining of endothelial cells with an isotype matching control IgG was included as a negative control. (C-E) Kinetics of endothelial cell GRP78 expression in response to BHB (C), glucose (D), or iron (E) as quantified by qRT-PCR. Data in qRT-PCR ( $n=6$ from 2 independent experiments for each figure) are expressed as median \pm interquartile range. ${ }^{*} P<0.004$ vs. $0 \mathrm{mM} \mathrm{BHB} ;{ }^{* *} P<0.01$ vs. 0 or $5 \mathrm{mM} \mathrm{BHB} ;{ }^{\ddagger} P<0.02$ vs. 0,5, or $10 \mathrm{mM} B H B ;{ }^{\S} P<0.005$ vs. no stimulus at each time point; ${ }^{\sharp \#} P<0.05$ vs. $50 \mu \mathrm{M} \mathrm{FeCl}_{3}$ or $10 \mathrm{mM} \mathrm{BHB}$ at 6 hours; ${ }^{\S} P<0.01 \mathrm{vs}$. $50 \mu \mathrm{M} \mathrm{FeCl}_{3}, 4 \mathrm{mg} / \mathrm{ml}$ glucose, or $10 \mathrm{mM} \mathrm{BHB}$ at 6 or 12 hours by Wilcoxon rank sum test.

administration unless the acidosis is severe (6), our results suggest that DKA patients with mucormycosis should have aggressive treatment to correct the acidosis.

\section{Results}

$B H B$, glucose, and iron enhance the expression of endothelial cell GRP78. We previously showed that excess free iron (15-50 $\mu \mathrm{M})$ and elevated glucose concentrations $(4-8 \mathrm{mg} / \mathrm{ml})$, often seen in patients with hyperglycemia and DKA, upregulate surface expression of endothelial cell GRP78, which results in enhanced R. oryzae invasion and subsequent damage of endothelial cells (5). We have expanded these studies to investigate the effect of BHB (as a representative of human ketone bodies) on the expression of the receptor. Patients with ketoacidosis have a serum BHB concentration that ranges from approximately 5 to $20 \mathrm{mM}$ (7). Therefore, we tested the effect of these concentrations on endothelial cell GRP78 mRNA expression. We found that at $5 \mathrm{mM}$, BHB enhanced expression of GRP78 by 3-fold and that higher concentrations of BHB increased GRP78 expression by 9 -fold at $20 \mathrm{mM}$ (Figure 1A). In addition, flow cytometric analysis of endothelial cells stained with an anti-GRP78 antibody demonstrated that exposure to BHB increased the expression of GRP78 on the cell surface (Figure 1B).

Next, we studied the effects of BHB, glucose, and iron on the kinetics of the enhanced GRP78 expression. Endothelial cells incubated with physiological concentrations of BHB $(10 \mathrm{mM})$ (Figure 1C), glucose (4 mg/ml) (Figure 1D), or $\mathrm{FeCl}_{3}(50 \mu \mathrm{M})$ (Figure
1C) had 2- to 3-fold enhanced expression of GRP78 mRNA as early as 6 hours, and GRP78 expression reached a peak of approximately 4- to 7 -fold after 24 hours and plateaued after 48 hours (Figure 1, $\mathrm{C}-\mathrm{E})$. Collectively, these results demonstrate that the expression of the endothelial cell receptor GRP78 protein is enhanced in cells exposed to elevated concentrations of BHB, glucose, and iron often seen with patients uniquely predisposed to mucormycosis.

Elevated concentrations of $B H B$, glucose, and iron enhance R. oryzae CotH expression. Because the surface cell CotH proteins act as unique ligands that enable Mucorales to invade host cells via binding to GRP78 (4), we studied the effect of clinically relevant concentrations of BHB ( 5 and $20 \mathrm{mM}$ ), glucose $(4$ and $8 \mathrm{mg} / \mathrm{ml})$, and $\mathrm{FeCl}_{3}(15$ and $50 \mu \mathrm{M})(8)$ on the expression of $\mathrm{CotH}$ genes and their encoded proteins after 24 hours of incubation. CotH3 and $\mathrm{CotH} 2$ were studied because both of their gene products bind GRP78 (4). BHB at $5 \mathrm{mM}$ enhanced the expression of $\mathrm{CotH} 2$ or $\mathrm{CotH} 3$ by a 2to 4-fold increase while BHB at $20 \mathrm{mM}$ resulted in a 4- to 6-fold increase in the expression of these 2 genes, respectively. Exposure to $\mathrm{BHB}$ at $20 \mathrm{mM}$ even enhanced expression of both genes over that in cells that had been exposed to BHB at $5 \mathrm{mM}$. Interestingly, the expression of CotH3 in particular, which is the main invasin in $R$. oryzae (4), was drastically increased in response to BHB (Figure 2A). Similarly, incubating $R$. oryzae germlings with glucose at 4 or $8 \mathrm{mg}$ / $\mathrm{ml}$ led to a 3- to 5-fold increase in expression of $\mathrm{CotH} 2$ and $\mathrm{CotH} 3$, versus cells incubated in the normal concentration of glucose at $1 \mathrm{mg} / \mathrm{ml}$. However, there was no significant enhancement in $\mathrm{CotH}$ 
A

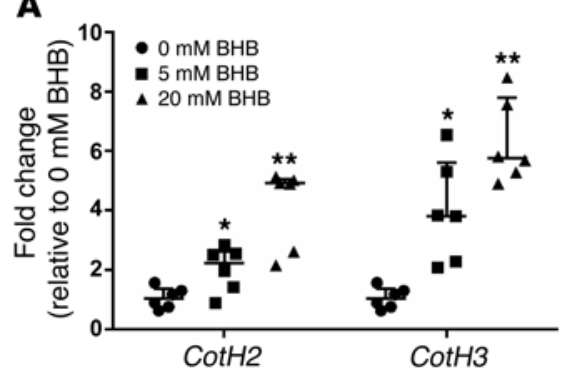

D

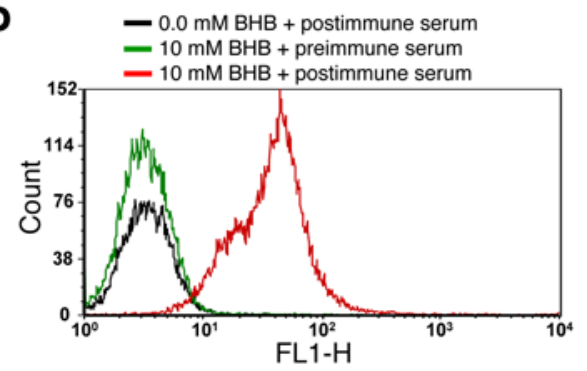

B

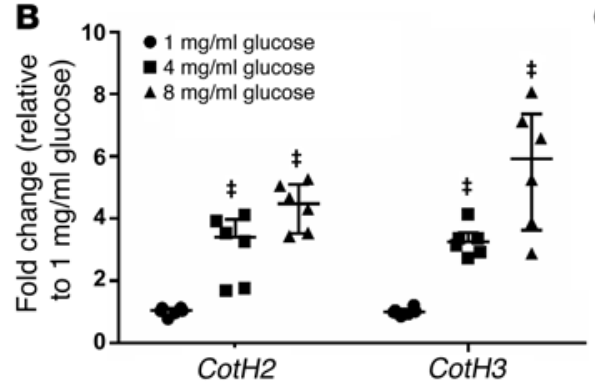

E $\quad-1 \mathrm{mg} / \mathrm{ml}$ glucose cells + postimmune serum E $\quad-1 \mathrm{mg} / \mathrm{ml}$ glucose cells + postimmune serum

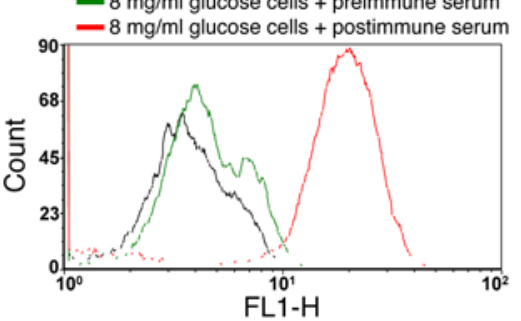

C

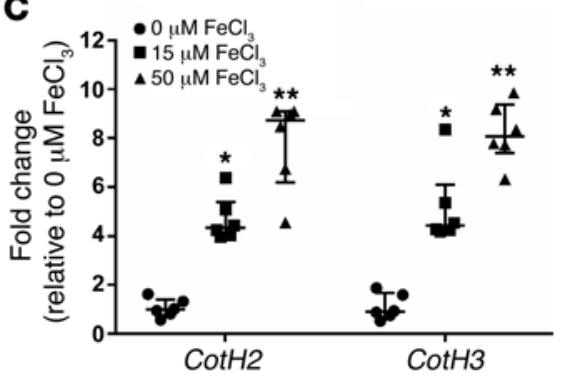

F $\quad-0 \mu \mathrm{M} \mathrm{FeCl}_{3}$ cells + postimmune serum F $\begin{aligned} & -0 \mu \mathrm{M} \mathrm{FeCl}_{3} \text { cells + postimmune serum } \\ & -50 \mu \mathrm{M} \mathrm{FeCl}_{3} \text { cells + preimmune serum }\end{aligned}$

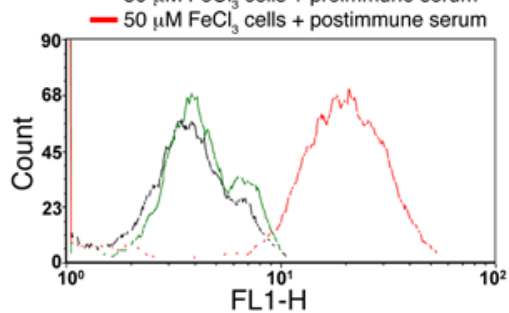

G

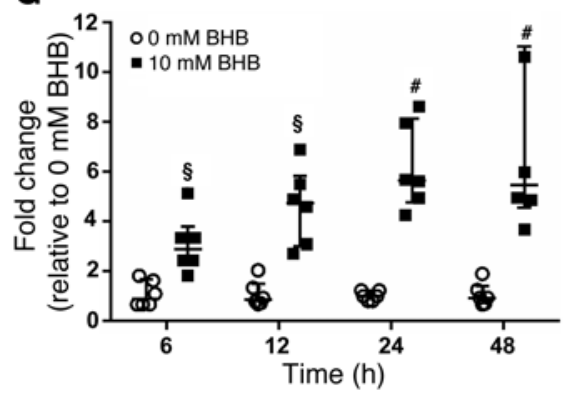

H

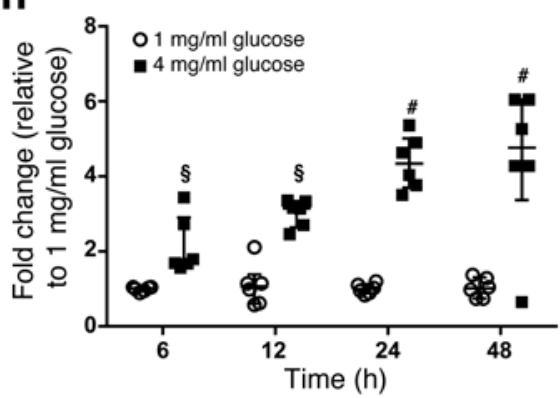

I

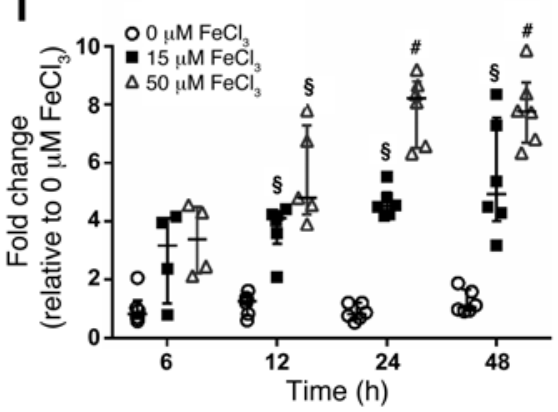

Figure 2. BHB, glucose, and iron concentrations consistent with those seen in DKA patients induce expression of CotH proteins in a time- and concentration-dependent manner. (A-C) R. oryzae cells were incubated at various concentrations of BHB (A), glucose (B), or iron (C) often seen in DKA patients for 24 hours; then the expression of CotH genes was quantified by real-time RT-PCR (normalized to ACT1 housekeeping gene). (D-F) CotH protein cell surface expression in response to BHB (D), glucose (E), or iron (F) after 4 hours of incubation was quantified using FACS analysis following staining with anti-CotH polyclonal antibodies raised against CotH peptide in rabbits (primary antibody), then counterstaining with anti-rabbit Alexa Fluor 488-labeled antibody. Negative controls included staining of cells with serum collected from the same rabbit before vaccination with CotH peptide as primary antibody (preimmune serum). (G-I) Kinetics of cell surface $R$. oryzae CotH expression in response to elevated concentrations of BHB (C), glucose (H), or iron (I) as quantified by qRT-PCR. Data in qRT-PCR ( $n=4-6$ wells per group from 2 independent experiments) are expressed as median \pm interquartile range relative to CotH expression in $R$. oryzae cells incubated without stimulus (A, C, G, and I) or with $1 \mathrm{mg} / \mathrm{ml}$ glucose (B and $\mathbf{H}) .{ }^{*} P=0.04 \mathrm{vs} .0 \mu \mathrm{M} \mathrm{FeCl}{ }_{3}$ or $0 \mathrm{mM} \mathrm{BHB}$; ${ }^{* *} P \leq 0.02$ vs. 0 or $15 \mu \mathrm{M} \mathrm{FeCl}$ or $5 \mathrm{mM} \mathrm{BHB} ;{ }^{\ddagger} P<0.02 \mathrm{vs} .1 \mathrm{mg} / \mathrm{ml}$ glucose; ${ }^{\S} P<0.001$ vs. no stimulus or $1 \mathrm{mg} / \mathrm{ml}$ glucose at the specified time point; ${ }^{\#} P<0.05$ vs. same condition at 6 or 12 hours by Wilcoxon rank sum test.

gene expression when cells were incubated with $8 \mathrm{mg} / \mathrm{ml}$ glucose versus the concentration of $4 \mathrm{mg} / \mathrm{ml}$ (Figure 2B). Finally, incubating $R$. oryzae with 15 or $50 \mu \mathrm{M} \mathrm{FeCl}_{3}$ resulted in a 4 - and 7 -fold increase in $\mathrm{CotH} 2$ and $\mathrm{Cot} \mathrm{H} 3$ expression, respectively (Figure 2C).

To confirm that increased gene expression resulted in increased protein expression on the cell surface of R. oryzae, we performed flow cytometry analysis using anti-CotH antibodies raised against a peptide shared among $\mathrm{CotH} 2$ and $\mathrm{CotH} 3$ proteins (4) to quantify the amount of $\mathrm{CotH}$ expression on the cell surface of organisms exposed to $\mathrm{BHB}$, glucose, or iron. We found that elevated concentrations of $\mathrm{BHB}$, glucose, or iron resulted in increased CotH expression on the cell surface (Figure 2, D-F).

Since CotH3 is the main invasin that binds to GRP78 (4), we studied the kinetics of its expression in response to BHB, glucose, or iron by quantitative reverse transcriptase PCR (qRT-PCR). Con- siderable enhancement of $\mathrm{Cot} H 3$ gene expression was detected as early as 6 hours after incubation regardless of the stimulus used and continued to increase gradually for 24 hours after incubation, after which the expression plateaued (Figure 2, G-I).

Enhanced expression of GRP78 and $\mathrm{CotH}$ is specific to BHB. Next, we investigated whether the enhanced expression of GRP78 and CotH proteins is specific to BHB or part of a general stress response. We incubated endothelial cells or R. oryzae with different acids, including BHB, lactic acid (as a representative of lactic acidosis), or $\mathrm{HCl}$ (as a representative of acidosis due to inorganic acids), before determining the level of expression of GRP78 or CotH3 by qRT-PCR. These studies were conducted in the absence of serum to eliminate any interfering effect of released iron from transferrin. All acid treatments resulted in a $\mathrm{pH}$ drop in the medium from 7.4 to 6.8. Only BHB treatment was able to increase the expression of 
A

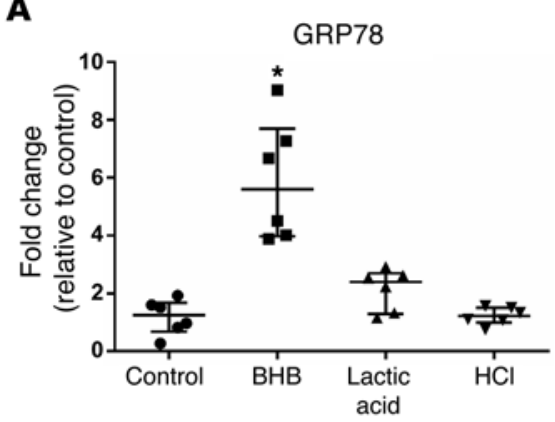

C

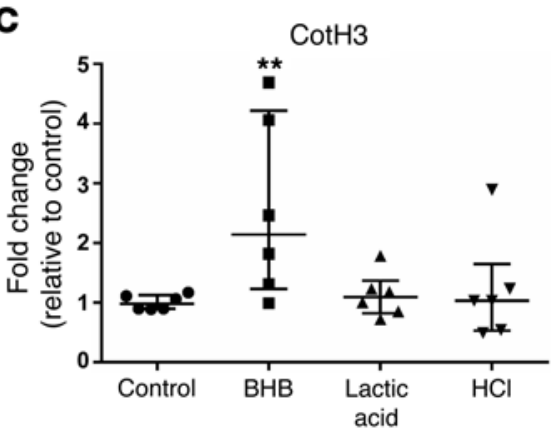

B

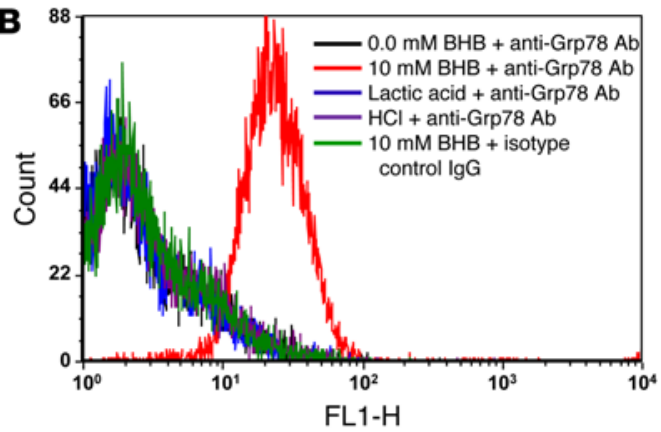

D

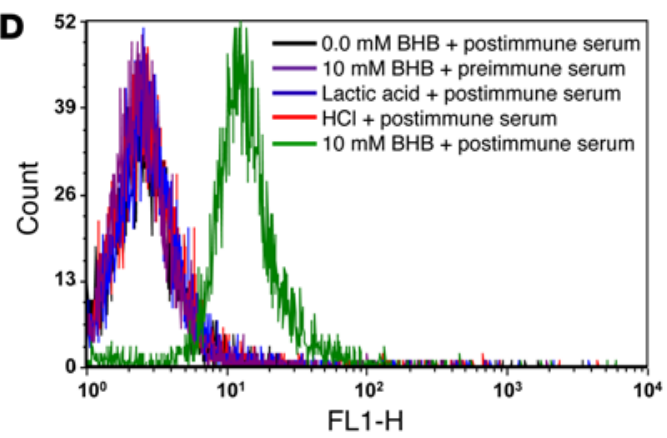

Figure 3. Induction of GRP78 or CotH3 expression is specific to BHB. $R$. oryzae or endothelial cells were incubated with $10 \mathrm{mM} \mathrm{BHB}$, lactic acid, or $\mathrm{HCl}$ for 6 hours in the absence of serum. All acid treatments resulted in dropping of the $\mathrm{pH}$ of the medium to 6.8. The expression of GRP78 (A) or CotH3 (C) was quantified by real-time RT-PCR after normalization of the data to GADPH or ACT1 housekeeping genes, respectively. GRP78 (B) or CotH3 (D) protein surface expression on endothelial or fungal cells using the above conditions was quantified using FACS analysis following staining with anti-GRP78 antibodies or CotH polyclonal antibodies (postimmune serum), respectively. Negative controls included staining of cells with an isotype matching control IgC (for GRP78 detection in B) or with serum collected from the same rabbit before vaccination with CotH peptide as primary antibody (preimmune serum in D). Data in qRT-PCR ( $n=6$ wells per group from 2 independent experiments) are expressed as median \pm interquartile range relative to $G R P 78$ or CotH3 expression in endothelial or $R$. oryzae cells, respectively, incubated in the media without any of the acids (Control). ${ }^{*} P<0.003$ vs. all other treatments; ${ }^{* *} P<0.05$ vs. control or lactic acid by Wilcoxon rank sum test.

GRP78 and CotH3 by 5- and 2.5-fold, respectively, in comparison with control cells without acid treatment (Figure $3, \mathrm{~A}$ and C). These results were also corroborated with the enhanced detection of cell surface expression of GRP78 and CotH3 by flow cytometry (Figure $3, \mathrm{~B}$ and $\mathrm{D})$. These findings strongly indicate that the enhanced expression of GRP78 and CotH3 is specific to ketoacidosis mediators (e.g., BHB) and is not part of a general stress response.

Enhanced expression of GRP78 and CotH is mainly driven by $B H B$ and iron. Because DKA patients are uniquely predisposed to mucormycosis and concurrently have poorly controlled hyperglycemia, acidosis, and elevated available serum iron, we compared the combined effects of glucose, $\mathrm{BHB}$, and iron with that of each stimulus alone on the induction of GRP78 or $\mathrm{CotH}$ mRNA expression. BHB and iron induced greater expression of host GRP78 than did glucose. However, when all 3 stimuli were combined, GRP78 expression was similar to that of cells that have been exposed to either BHB or iron alone (Figure 4A). Furthermore, supplementation of growth medium with elevated concentrations of BHB, glucose, and iron induced a similar increase of fungal CotH mRNA expression over that in fungal cells that were grown in medium without supplementation. When the effect of each stimulus was compared with the combined effect of the 3 stimuli on the expres- resulted in a small (27\%) but significant increase in adherence (i.e., cell-association) of R. oryzae to the host cells, whereas exposure of the fungus to BHB prior to interaction with endothelial cells slightly increased adhesion by $10 \%$. Furthermore, exposing both endothelial cells and R. oryzae to BHB resulted in an additive increase of approximately $40 \%$ in adherence of $R$. oryzae to endothelial cells (Figure 5A). In contrast, exposure of endothelial cells, $R$. oryzae, or both cell types to elevated glucose or iron concentrations prior to the conducting of the interaction assay had no effect on adherence of the fungus to endothelial cells (Figure 5B for glucose and Figure $5 \mathrm{C}$ for iron).

More profound effects were noticed with the ability of $R$. oryzae to invade endothelial cells. For example, endothelial cells exposed to BHB, glucose, or iron were more susceptible to invasion by $R$. oryzae, with approximately $100 \%, 40 \%$, and $50 \%$ increases in invasion, respectively, compared with cells that had not been exposed (Figure 5, A-C). However, exposure of R. oryzae to BHB or iron, but not glucose, enhanced invasion by $30 \%$ to $40 \%$ compared with control (i.e., no exposure of host or fungal cells to stimulus) (Figure 5, A and C). Although exposure of both cell types to either of the stimuli resulted in enhanced invasion of $R$. oryzae to endothelial cells, this enhanced invasion was not greater than 
A

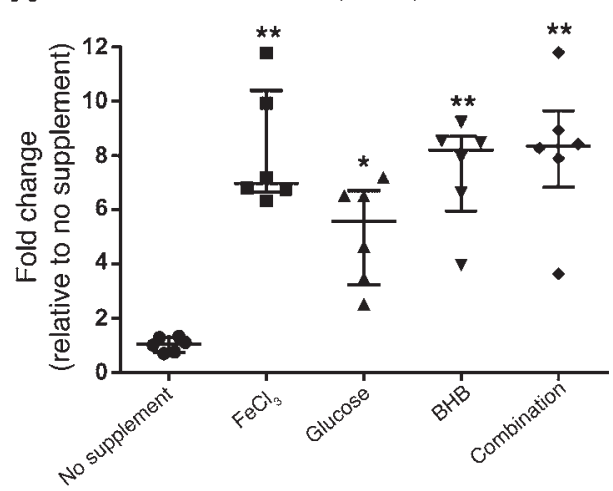

B

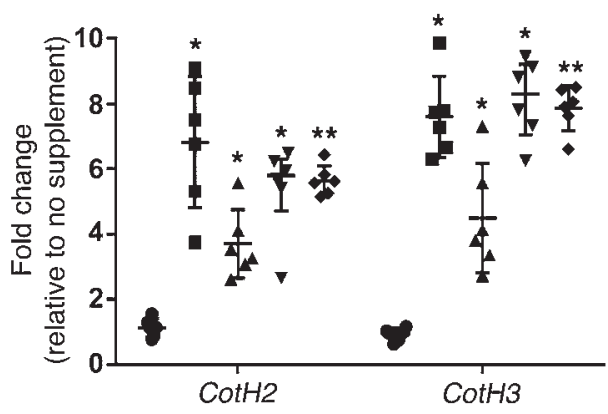

Figure 4. The combined effect of iron, glucose, and BHB had no additive effect on the endothelial cell GRP78 or the fungal CotH2 or CotH3 expression. Endothelial cells (A) or $R$. oryzae (B) were exposed to iron $(50 \mu \mathrm{M})$, glucose $(4 \mathrm{mg} / \mathrm{ml})$, or BHB $(10 \mathrm{mM})$ alone or in combination for 24 hours before extraction of total RNA and quantification of GRP78 or CotH2 or CotH3 expression by qRT-PCR relative to GADPH or ACT1 housekeeping genes, respectively. Data ( $n=6$ per arm from 2 independent experiment) are presented as median \pm interquartile range. ${ }^{*} P<0.001$ vs. no supplement; ${ }^{*} P<0.05$ vs. no supplement and glucose.

the invasion noticed when the endothelial cells were exposed to the stimuli (Figure 5, A-C).

Because, as we previously showed, endothelial cell injury is reliant on the ability of the fungus to invade the host cells (3), the invasion results were almost completely mirrored in the damage assay. Briefly, the enhanced surface expression of GRP78 due to exposure of endothelial cells augmented the ability of $R$. oryzae to injure endothelial cells regardless of the stimuli used when compared with control (Figure 5, D-F). However, BHB- or iron-stimulated endothelial cells were more vulnerable to R. oryzae-induced injury than endothelial cells stimulated with glucose (80\%-100\% increase in injury to iron- and BHB-exposed cells vs. $40 \%$ to glucose-exposed cells) (Figure 5, D and F). Additionally, R. oryzae exposed to iron or BHB, but not glucose, resulted in enhanced injury to endothelial cells when compared with control treatment (Figure 5E). Importantly, and in contrast to exposure to elevated glucose or BHB concentrations, it appears that dual exposure of the host and the pathogen to elevated concentration of iron results in slight enhancement in endothelial cell injury compared with injury induced after exposure of the fungus or the host to iron (Figure 5F).

Collectively, these data indicate that the elevated concentrations of BHB and iron, and to a lesser extent glucose, result in upregulation of both the GRP78 receptor and the CotH fungal ligand, which enhances the invasion of and subsequent damage to endothelial cells. Additionally, invasion and damage to host cells are driven more by upregulation of the receptor GRP78 than the CotH ligand.

$B H B$ enhances the growth of $R$. oryzae in vitro and reduces its neutrophil-mediated killing ex vivo. Because $\mathrm{BHB}$ appears to be a major modulator of $R$. oryzae-endothelial cell interactions via influencing GRP78 and CotH3 expression, we wanted to investigate whether $\mathrm{BHB}$ modulates factors that are likely to contribute to the course of infection (e.g., fungal growth and/or fungus killing by neutrophils). Incubating R. oryzae spores with $10 \mathrm{mM} \mathrm{BHB}$ resulted in acidification of the medium, while addition of $\mathrm{NaHCO}_{3}$ reversed the $\mathrm{pH}$ back to its normal level (Figure 6A). This acidification of the medium was accompanied by significant enhancement in the fungus growth at 4-6 hours after incubation. Further, addi- tion of $\mathrm{NaHCO}_{3}$ reversed this enhanced growth to levels similar to those detected with medium without BHB (Figure 6B). These results were also confirmed by measurement of the diameter of colonies of $R$. oryzae after 16 hours of incubation with or without $\mathrm{BHB}, \mathrm{NaHCO}_{3}$, or $\mathrm{BHB}+\mathrm{NaHCO}_{3}$ (Figure 6C). $\mathrm{NaHCO}_{3}$ had no effect on the growth of $R$. oryzae (Figure 6, B and C).

Earlier reports indicated that $\mathrm{BHB}$ attenuates the ability of neutrophils to kill E. coli (9). Thus, we evaluated the effect of BHB on neutrophil-mediated killing of $R$. oryzae. Not only did incubation of human neutrophils with $10 \mathrm{mM}$ of BHB completely reverse the ability of phagocytes to kill $R$. oryzae, it actually enhanced the growth of the fungus as anticipated from our growth studies above. However, the addition of $\mathrm{NaHCO}_{3}$ completely reversed the inhibitory effect of $\mathrm{BHB}$ on the neutrophil function (Figure 6D). The inhibitory effect of BHB on neutrophil function can be explained, at least in part, by the ability of BHB to block the production of ROS (Figure 6E). Collectively, these results show that BHB enhances growth of R. oryzae and suppresses neutrophilmediated killing of the fungus.

$B H B$ enhances $R$. oryzae virulence in mice due to overexpression of host GRP78 and R. oryzae CotH. To investigate whether our in vitro observations are relevant to mucormycosis pathogenesis, we compared the susceptibility of immunocompetent normal mice versus mice given $\mathrm{BHB}$ to $R$. oryzae infection. Repeatedly injecting normal mice with $\mathrm{BHB}$ resulted in a drop of serum $\mathrm{pH}$ from 7.3 to 6.8 (Figure 7A) and increased serum BHB from approximately $0.75 \mathrm{mM}$ to $3.0 \mathrm{mM}$ (Figure 7B). Additionally, concordant with the upregulation of $G R P 78$ expression by BHB in vitro, mice receiving repeated doses of $\mathrm{BHB}$ were found to express a 2- to 4-fold higher level of GRP78 mRNA in target organs that included sinus, lungs, and brain as compared with normal mice (Figure 7C). The BHBtreated mice were found to be extremely susceptible to $R$. oryzae infection initiated by intratracheal inoculation with median survival time of 5 days and $90 \%$ mortality by day 6 after infection versus normal mice that had been infected with the same inoculum or versus uninfected BHB-treated mice, which had almost a $100 \%$ survival (Figure 7D). In support of these data, BHB-treated mice infected with $R$. oryzae had an approximately 1-log increase 
Adherence and endocytosis

A
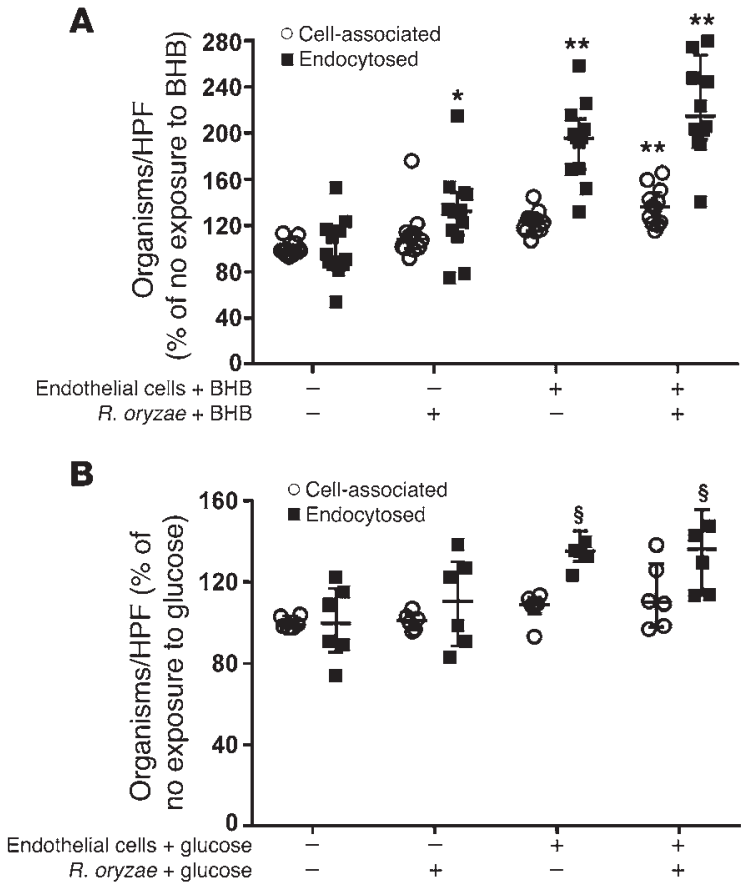

C

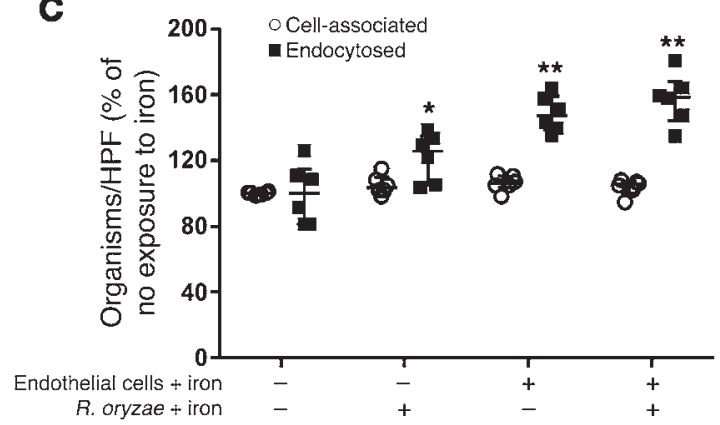

Damage

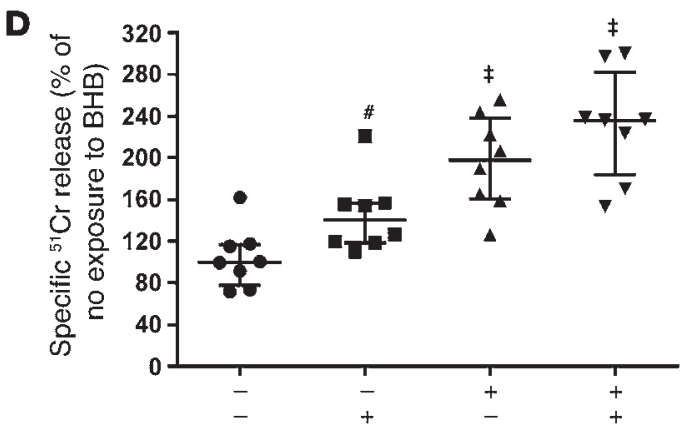

E

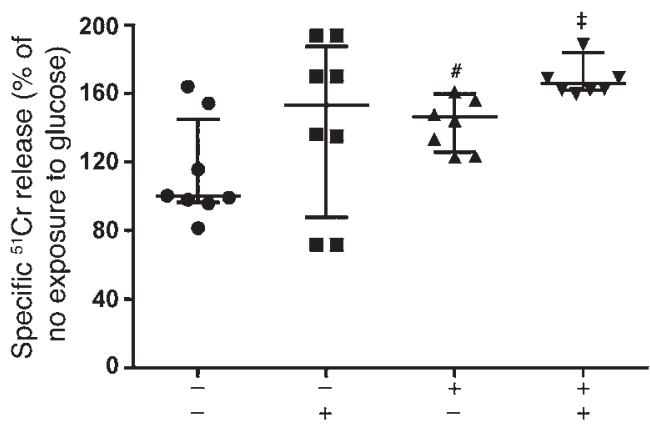

$\mathbf{F}$

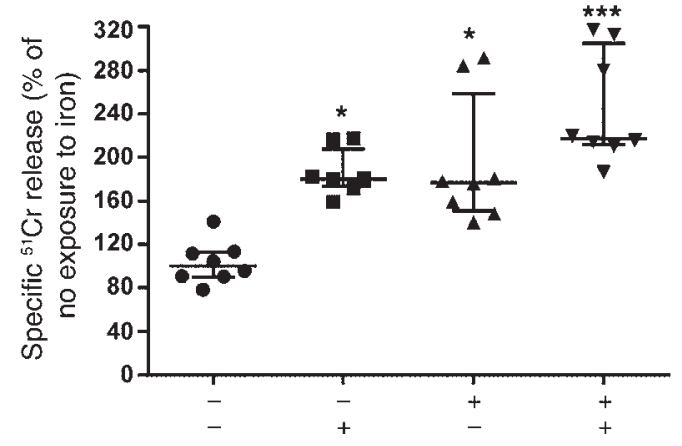

Figure 5. BHB, glucose, or iron concentrations seen in DKA patients enhanced invasion of and damage to endothelial cells by $R$. oryzae. Endothelial cells, $R$. oryzae germlings, or both were exposed to $10 \mathrm{mM} \mathrm{BHB}(\mathbf{A}$ and $\mathbf{D}), 4 \mathrm{mg} / \mathrm{ml}$ glucose (B and $\mathbf{E})$, or $15 \mu \mathrm{M}$ of iron (C and $\mathbf{F})$ and subsequently evaluated for adherence (cell-association), invasion (endocytosis), or damage ( ${ }^{51} \mathrm{Cr}$-release assay). Endocytosis data were derived from more than 600 fungal cells interacting with approximately 200 endothelial cells in each group per experiment, with an average of $20 \%, 20 \%$, and $21 \%$ endocytosis for no BHB, 1 mg/ $\mathrm{ml}$ glucose, or no $\mathrm{FeCl}_{3}$, respectively. ${ }^{*} P<0.05$ vs. no exposure of endothelial cells or $R$. oryzae to $\mathrm{BHB}$ or iron; ${ }^{* *} P<0.01$ vs. (a) no exposure of endothelial cells or $R$. oryzae to $\mathrm{BHB}$ or $R$. oryzae exposed to $\mathrm{BHB}$ or (b) no exposure of endothelial cells or $R$. oryzae to iron or $R$. oryzae exposed to iron; ${ }^{\#} P<0.02$ vs. no exposure of endothelial cells or $R$. oryzae to $\mathrm{BHB} ;{ }^{\ddagger} P<0.05$ vs. no exposure of endothelial cells or $R$. oryzae to $\mathrm{BHB}$ or $R$. oryzae exposed to $\mathrm{BHB}$; ${ }^{\S} P<0.03$ vs. no exposure of endothelial cells or $R$. oryzae to $4 \mathrm{mg} / \mathrm{ml}$ glucose; ${ }^{\#} P<0.05 \mathrm{vs}$. no exposure of endothelial cells or $R$. oryzae to $4 \mathrm{mg} / \mathrm{ml}$ glucose; ${ }^{\ddagger} P<0.02$ vs. endothelial cells exposed to $4 \mathrm{mg} / \mathrm{ml}$ glucose; ${ }^{* *} P<0.05 \mathrm{vs}$. no exposure of endothelial cells or $R$. oryzae to iron or vs. endothelial cells or $R$. oryzae exposed to iron. Statistical analysis was carried out using Wilcoxon rank sum test. $n=12$ and 6 slides per group from 3 experiments for endocytosis with BHB and endocytosis with glucose or iron, respectively. $n=8$ wells per group from 3 independent experiments for the damage assay. Data are expressed as median \pm interquartile range. HPF, high-power field.

in fungal burden in the lungs and brain (primary and secondary target organs, ref. 4) compared with the same organs recovered from infected immunocompetent mice (Figure 7E). Organs recovered from normal mice after the duration of the experiment (i.e., 21 days after infection) had no traces of fungal elements as determined by tissue culturing (data not shown).

Because BHB enhanced CotH3 expression in vitro, we compared the level of $\operatorname{CotH} 3$ mRNA in lungs and brain homogenate of BHB-treated and infected mice versus organ homogenate collected from normal mice infected with $\mathrm{R}$. oryzae. CotH3 expres- sion was 1.5- to 2.0-fold higher in brain and lungs of BHB-treated mice versus untreated mice (Figure 7F). Collectively, our in vivo data clearly demonstrate an enhanced virulence of $R$. oryzae in BHB-treated mice over normal mice, which is due, at least in part, to upregulation of host GRP78 and fungal CotH3 expression.

To investigate whether BHB treatment specifically predisposed mice to mucormycosis, susceptibility of BHB-treated mice was compared with that of immunosuppressed (neutropenic) mice in contracting invasive pulmonary aspergillosis via inhalation (10). As we previously reported, neutropenic mice were sus- 
A

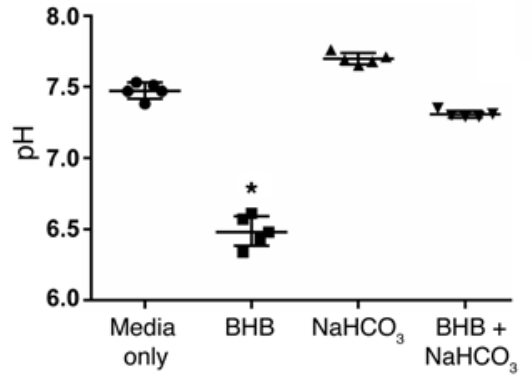

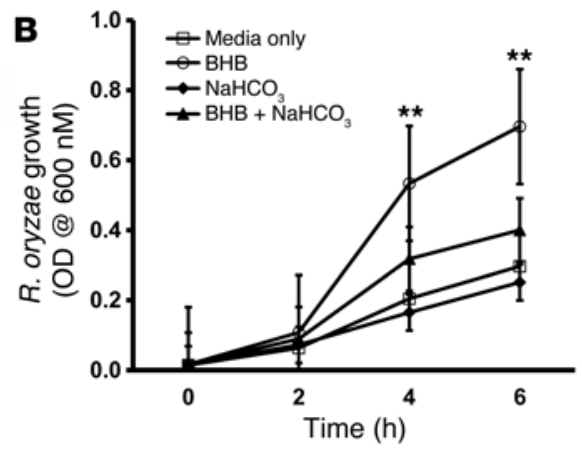

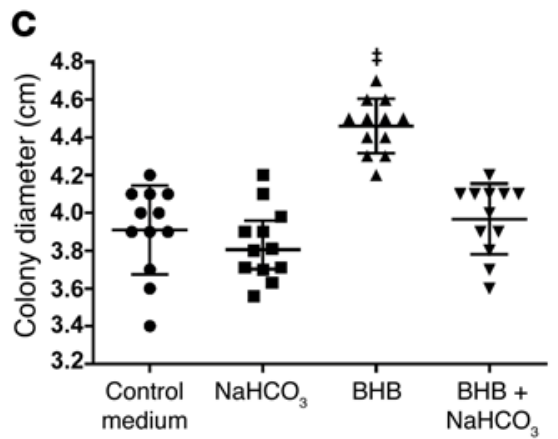

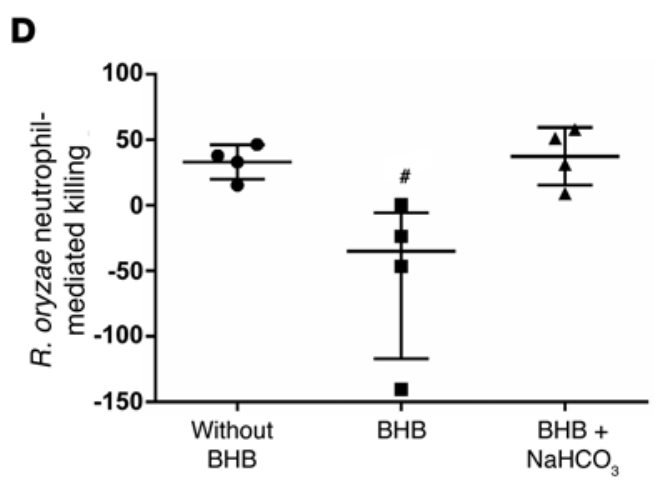

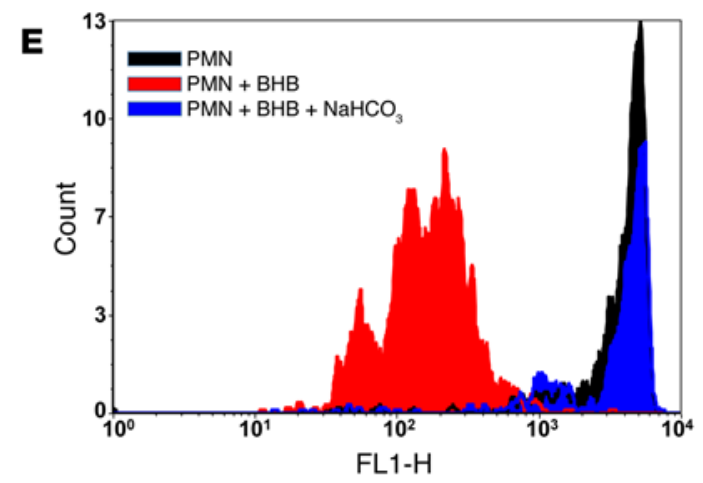

Figure 6. BHB augments growth of $\boldsymbol{R}$. oryzae and attenuates neutrophil functions. (A) $R$. oryzae spores $\left(5 \times 10^{5} / \mathrm{ml}\right)$ were grown in RPMI-1640 without phenol red supplemented with $10 \mathrm{mM} \mathrm{BHB}, 26 \mathrm{mM} \mathrm{NaHCO}_{3}$, or both, which resulted in modulation of the media pH. (B) Growth of $R$. oryzae was measured spectrophotometrically at $600 \mathrm{~nm}$ over time ( $n=12$ for each time point per each group). (C) $R$. oryzae spores ( $10^{5}$ per $\left.10 \mu \mathrm{l}\right)$ were plated on RPMI- 1640 without phenol red supplemented with $\mathrm{BHB}$ or $\mathrm{BHB}+\mathrm{NaHCO}_{3}$ agar plates $(n=12$ per arm), and the diameter of the colony was measured 24 hours after incubation at $37^{\circ} \mathrm{C}$. (D) The effects of $\mathrm{BHB}$ or $\mathrm{BHB}+\mathrm{NaHCO}_{3}$ on human neutrophil inhibition of $R$. oryzae (1:10, effector/target ratio) were analyzed using XTT assay $(n=4$ per arm). (E) The effects of $\mathrm{BHB}$ or $\mathrm{BHB}+\mathrm{NaHCO}_{3}$ on the ability of human neutrophils to produce ROS were analyzed using flow cytometry after addition of DHR123. ${ }^{*} P<0.015$ vs. all other groups; ${ }^{* *} P<0.001$ vs. all other groups; ${ }^{\ddagger} P<0.002$ vs. all other groups; ${ }^{*} P<0.05$ vs. the 2 other treatments.

ceptible to aspergillosis infection with median survival time of 10 days and $90 \%$ mortality by day 17 after infection. However, BHBtreated mice were largely resistant to pulmonary invasive aspergillosis, with $90 \%$ of the mice surviving the infection and appearing healthy (Figure 7D).

$\mathrm{NaHCO}_{3}$ protects endothelial cells from $\mathrm{R}$. oryzae-enhanced injury due to $\mathrm{BHB}$ exposure and reverses mucormycosis pathogenesis in vivo. $\mathrm{NaHCO}_{3}$ is commonly used to correct severe acidosis of $\mathrm{pH}$ less than $6.9(11,12)$. Additionally, the lower $\mathrm{pH}$ in DKA hosts compromises the ability of transferrin to chelate iron (8), which induces the expression of GRP78 (5) and CotH (Figure 2) and thereby enhances invasion and subsequent damage of the endothelium. Therefore, we investigated whether $\mathrm{NaHCO}_{3}$ and the iron chelator phenanthroline could reverse the enhanced invasion and subsequent damage to endothelial cells caused by $R$. oryzae when incubated with BHB. GRP78 expression by endothelial cells that had been exposed to $\mathrm{BHB}$ or $\mathrm{BHB}+\mathrm{NaHCO}_{3}$ was evaluated using anti-GRP78 antibody by flow cytometry. As expected, endothelial cells incubated with BHB expressed higher levels of GRP78 on their cell surface than cells that were not exposed to the ketone body. Importantly, $\mathrm{NaHCO}_{3}$ reversed this enhanced expression to the normal levels detected (Figure 8A).

Next, the interactions of $R$. oryzae with endothelial cells were studied in the presence of $\mathrm{BHB}, \mathrm{BHB}+\mathrm{NaHCO}_{3}, \mathrm{BHB}+$ phenanthroline, or $\mathrm{BHB}+\mathrm{NaHCO}_{3}+$ phenanthroline. Addition of $\mathrm{BHB}$ resulted in acidification of the assay medium from $\mathrm{pH} 7.5 \pm 0.1$ to $\mathrm{pH} 6.9 \pm 0.1$. Further, applying $\mathrm{NaHCO}_{3}$ raised the $\mathrm{pH}$ to the normal level of $7.5 \pm 0.2$. Acidification of the assay medium with $\mathrm{BHB}$ resulted in a significant increase in invasion and damage of endothelial cells by $R$. oryzae (Figure 8, B and C). Addition of $\mathrm{NaHCO}_{3}$ or phenanthroline partially protected endothelial cells from the BHB-enhanced invasion by R.oryzae. Also, combination of $\mathrm{NaHCO}_{3}$ and phenanthroline completely reversed the effect of BHB on R. oryzae-mediated invasion of (Figure $8 \mathrm{~B}$ ) and subsequent damage to the endothelium (Figure $8 \mathrm{C}$ ). Collectively, these results indicate that $\mathrm{BHB}$ modulates $\mathrm{R}$. oryzae-endothelial cell interactions by both lowering the $\mathrm{pH}$ and increasing free iron. Additionally, reversal of the acidification of the milieu coupled with iron chelation protects against $R$. oryzae-induced invasion and subsequent damage of the endothelium.

To investigate whether these in vitro results translated into the mouse model of mucormycosis, we treated mice with $\mathrm{BHB}$ or $\mathrm{BHB}+\mathrm{NaHCO}_{3}$ before infecting them with $\mathrm{R}$. oryzae. Addition of $\mathrm{NaHCO}_{3}$ to $\mathrm{BHB}$-treated mice reversed blood serum $\mathrm{pH}$ from approximately 6.8 to normal levels of approximately 7.2 (Figure 9A). In addition, administering BHB to immunocompetent mice increased labile plasma iron (LPI) 10 -fold to $10 \mu \mathrm{M}$ in comparison with untreated mice. In contrast, mice treated with $\mathrm{BHB}+\mathrm{NaHCO}_{3}$ had LPI concentrations similar to those of the untreated mice (Figure 9B). Therefore, BHB treatment lowers 
A
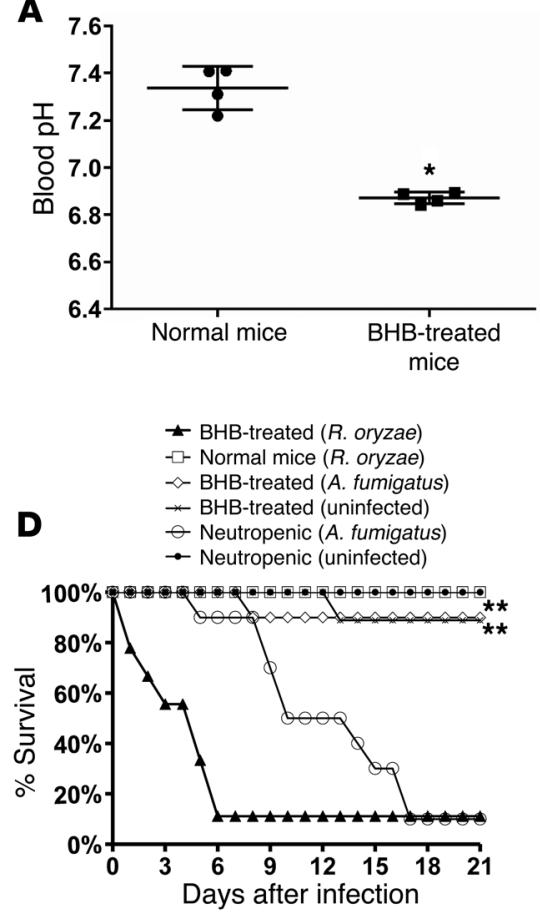

B

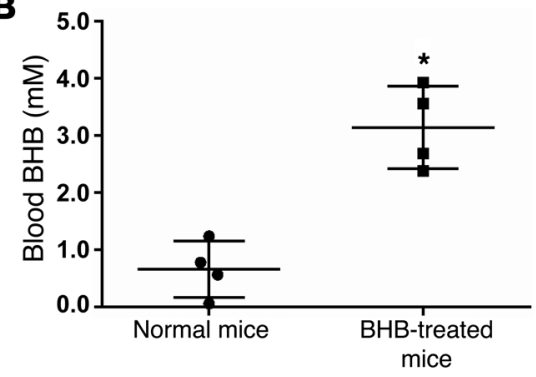

$\mathbf{E}$

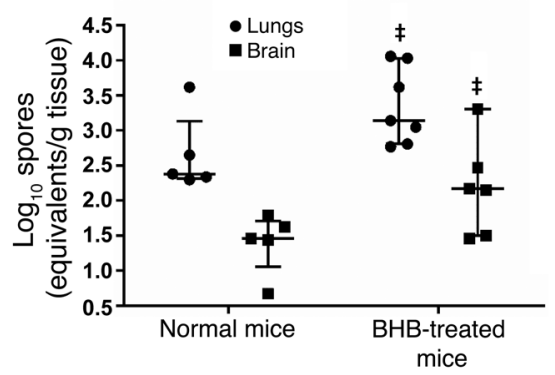

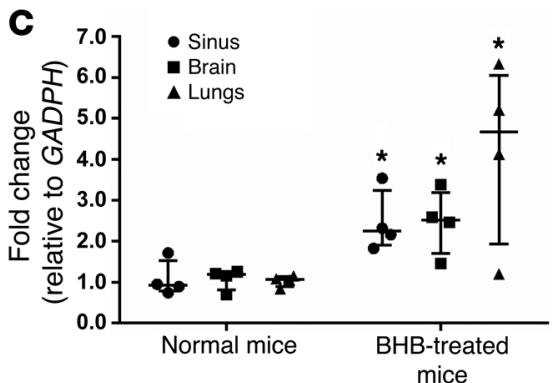

$\mathbf{F}$

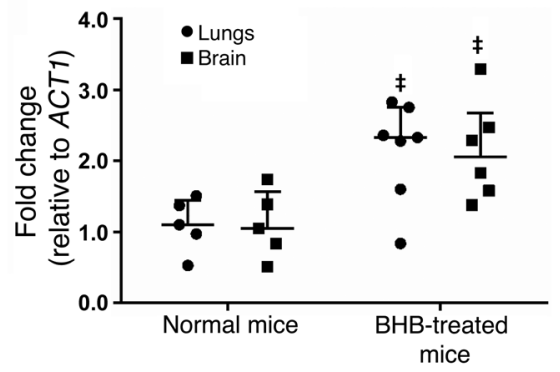

Figure 7. BHB administration in mice lowers blood pH, increases GRP78 expression in target organs, and specifically enhances susceptibility to mucormycosis. (A-C) Normal mice were injected 5 times with $5 \mathrm{mg} \mathrm{BHB} \mathrm{(} n=4$ mice per group) before determination of the blood pH (A), the concentration of BHB in the serum (B), and the expression of GRP78 in target organs (C). ${ }^{*} P<0.05$ vs. normal mice. (D and E) BHB-treated or normal mice $(n=10$ for BHBtreated and 8 for normal mice from 2 experiments) were infected intratracheally with $R$. oryzae spores, and survival (D) and tissue fungal burden ( $n=5$ for normal mice and 7 for BHB-treated mice) in lungs or brain after 48 hours of infection (E) were determined as primary and secondary end points, respectively. Delivered $R$. oryzae inocula were $8 \times 10^{3}$ and $1 \times 10^{3}$ spores for the survival and tissue fungal burden experiments, respectively. (F) Expression of $R$. oryzae CotH expression in mouse organs was also determined using the same organs processed for tissue fungal burden. ${ }^{\ddagger} P<0.05$ vs. the corresponding organ from normal mice. BHB-treated or neutropenic mice $(n=10$ per arm) were also infected with $A$. fumigatus via inhalation (delivered inoculum $1.1 \times$ $10^{3}$ conidia), and survival of mice was determined (D). Uninfected BHB-treated $(n=8)$ or uninfected neutropenic mice $(n=5)$ were included in the survival studies as control arms (D). ${ }^{* *} P<0.001$ for: normal $R$. oryzae-infected mice vs. $R$. oryzae-infected BHB-treated mice; uninfected BHB-treated mice vs. R. oryzae-infected BHB-treated mice; A. fumigatus-infected BHB-treated mice vs. R. oryzae-infected BHB-treated mice; or A. fumigatus-infected BHBtreated mice vs. A. fumigatus-infected neutropenic mice. Data in $\mathbf{A}-\mathbf{C}, \mathbf{E}$, and $\mathbf{F}$ are expressed as median \pm interquartile range. $y$ axis value in $\mathbf{E}$ represents the lower limit of detection of the assay.

the blood $\mathrm{pH}$, which results in increased LPI concentrations, and $\mathrm{NaHCO}_{3}$ reverses this effect. Next, we investigated whether $\mathrm{NaHCO}_{3}$ can alleviate mucormycosis in BHB-treated mice. As shown in Figure 7D, mice treated with BHB were extremely sensitive to R. oryzae with median survival time of 4 days and $90 \%$ mortality by day 7 after infection. In contrast, the administration of $\mathrm{NaHCO}_{3}$ to BHB-treated mice in prophylactic or therapeutic modes protected these animals from mucormycosis, with approximately $75 \%$ of the mice surviving the infection (median survival time of $>21$ days) and looking healthy when the experiment was terminated on day 21 after infection (Figure 9C). The enhanced survival of mice receiving $\mathrm{BHB}+\mathrm{NaHCO}_{3}$ was accompanied by significant reduction in lung and brain fungal burden when compared with survival of mice receiving only BHB (Figure 9D). Finally, histopathological examination of lungs from BHB-treated and infected mice showed clear signs of pneumonia with neutrophilic infiltrate, hemorrhage, and tissue edema, while infected BHB-treated mice receiving $\mathrm{NaHCO}_{3}$ had significantly milder pneumonia (Figure 9E). Collectively, these results corroborate the in vitro protective effects found with reversal of acidosis using $\mathrm{NaHCO}_{3}$.
$R$. oryzae virulence in BHB-treated mice is reliant on $\mathrm{CotH}$ and the high-affinity iron permease (Ftr1) proteins. Because BHB induced the expression of CotH (Figure 4 and Figure 7F) and resulted in increased concentrations of LPI (Figure 9B), we hypothesized that $R$. oryzae with attenuated expression of CotH or Ftr1 proteins (Ftr1p is essential for uptake of free iron; ref. 13) should demonstrate reduced virulence in BHB-treated mice. Indeed, BHB-treated mice infected with $R$. oryzae mutants harboring RNAi constructs targeting CotH or FTR1 had enhanced survival compared with BHB-treated mice infected with $R$. oryzae transformed with empty plasmid, with mouse survival of $0 \%, 33 \%$, and $56 \%$ by day 21 after infection and median survival time of 5, 14, or $>21$ days for $R$. oryzae transformed with empty plasmid, CotH-targeting construct, or FTR1-targeting construct, respectively (Figure 9F). These results confirm the complex effect of BHB on the host-fungus interactions through elevating LPI to increase fungal iron uptake and via enhancing host tissue invasion by inducing surface expression of CotH.

\section{Discussion}

In the present study, we continued our investigations to determine what host factors in DKA influence the ability of $R$. oryzae to invade 

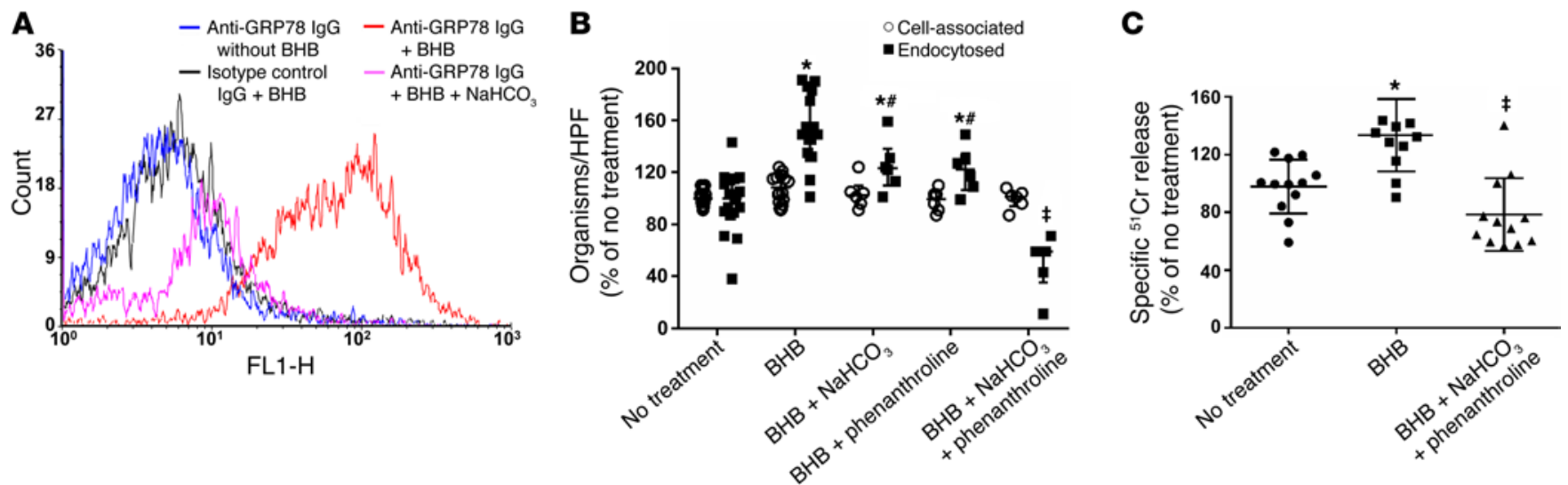

Figure 8. $\mathrm{NaHCO}_{3}$ bicarbonate protects endothelial cells from BHB-induced $R$. oryzae-enhanced invasion and subsequent injury. (A) Endothelial cell GRP78 surface expression was assessed in the presence of BHB with or without $\mathrm{NaHCO}_{3}$ after 5 hours of incubation by flow cytometry using anti-GRP78 antibodies. (B and C) Endothelial cells and $R$. oryzae were exposed separately to $\mathrm{BHB}, \mathrm{BHB}+\mathrm{NaHCO}_{3}, \mathrm{BHB}+$ phenanthroline, or $\mathrm{BHB}+\mathrm{NaHCO}+$ phenanthroline before testing of adherence to (cell-association) and invasion of (endocytosis) endothelial cells by $R$. oryzae (B), or $R$. oryzae-induced endothelial cell injury (C). (B) The endocytosis data were derived from more than 600 fungal cells interacting with approximately 200 endothelial cells in each group per experiment. (C) Damage assay was conducted for 4 hours in 96 -well plates. ${ }^{*} P<0.03$ vs. no treatment endocytosis or no treatment in the injury assay; ${ }^{\#} P<0.05$ vs. BHB endocytosis; ${ }^{\ddagger} P<0.05$ vs. endocytosis of all other treatment or no treatment or BHB in the injury assay. Statistical analysis was carried out using Wilcoxon rank sum test. $n \geq 6$ slides per group from 2 independent experiments for endocytosis, and $n=10-12$ wells per group from 2 independent experiments for the damage assay. Data are expressed as median \pm interquartile range.

host cells. In addition to the overexpression of the endothelial cell receptor GRP78, there was a marked enhanced cell surface expression of R. oryzae CotH proteins in the presence of elevated iron and glucose, at concentrations comparable to the ones encountered in patients with DKA $(5,8)$ in a time-dependent manner. We also showed that physiological concentrations of the ketone body BHB rapidly augmented the cell surface expression of both GRP78 and CotH proteins in a concentration- and time-dependent manner, which resulted in greater ability of $R$. oryzae to invade and subsequently damage endothelial cells in vitro. Of importance is the greater effect of BHB and iron on expression of GRP78 and the subsequent invasion and damage of the endothelium compared with the glucose effect. It is known that patients with DKA are uniquely predisposed to infection more than hyperglycemic patients $(1,2)$. Equally important is the finding that lactic acid did not induce the expression of GRP78 or CotH, hence confirming the specific effect of BHB on the host receptor and its fungal ligand. While other metabolic acidoses, such as lactic acidosis, are occasionally associated with mucormycosis $(14,15)$, ketoacidosis uniquely and more frequently predisposes patients to this infection $(1,2)$. Our data provide an explanation for the unique predisposition of DKA patients to mucormycosis. While general acidosis (be it due to lactic acidosis or ketoacidosis) results in release of iron from plasma iron-sequestering proteins, thereby making it available to invading organisms, only ketoacidosis induces the expression of GRP78 and CotH. This direct effect of BHB in enhancing GRP78/CotH interactions augments initiation and progression of the disease. Lactic acidosis present at the site of infection due to anaerobic conditions facilitated by tissue necrosis $(14,15)$ further worsens the outcome of any infection by providing much-needed iron to invading organisms but does not specifically predispose patients to mucormycosis infections. Additionally, acidic conditions prevalent at inflammatory loci further worsen any infection by suppressing the phagocyte-mediated killing mechanisms (16).
Another key finding was the greater effect of the enhancement of GRP78 expression on invasion of and damage to endothelial cells, compared with the overexpression of the CotH3 fungal invasin. This result is in agreement with the fact that $R$. oryzae must invade endothelial cells to cause damage (3) and anti-GRP78 antibodies almost completely block invasion of the endothelium by R. oryzae (5). Equally intriguing was that the enhanced effect on the host receptor and its fungal invasin by iron, glucose, and BHB occurred in the first 24 hours, after which the expression plateaued. This finding indicates that a patient having elevated concentrations of these stimuli is likely to become at risk of developing rapidly progressive mucormycosis within a short period of time, and emphasizes the importance of reversal of hyperglycemia, chelation of elevated available serum iron, and correction of acidosis as soon as possible.

Unlike iron and glucose, treating endothelial cells and R. ory$z a e$ with BHB showed enhanced ability of the fungus to adhere to endothelial cells. These results confirm our previous findings that adherence to and invasion of the endothelium are 2 independent processes mediated by different receptors $(4,5)$. Additionally, BHB must upregulate the expression of receptors controlling adhesion of the fungus to the endothelium. Studies to identify host and fungal receptors involved in the fungal adhesion to the endothelium are ongoing.

We have previously shown the relevance of our in vitro findings of enhanced endothelial cell GRP78 by using the diabetic mouse model in which increased available serum iron was detected (5), in a manner similar to the augmented levels of serum free iron in humans suffering from ketoacidosis (8). In the current study, the administration of BHB into immunocompetent mice simulated pathophysiological conditions seen in humans with DKA and mucormycosis. Namely, mice receiving BHB developed acidosis and had higher levels of BHB and free iron in their serum. These acidotic mice expressed more GRP78 in their tar- 
A

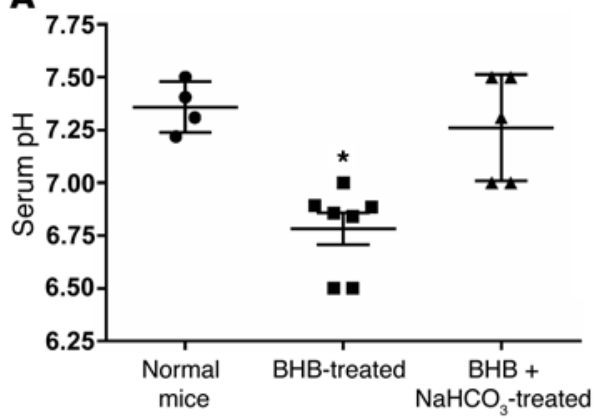

B

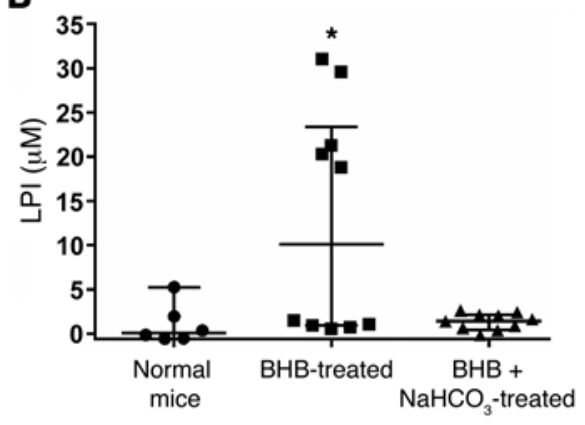

C

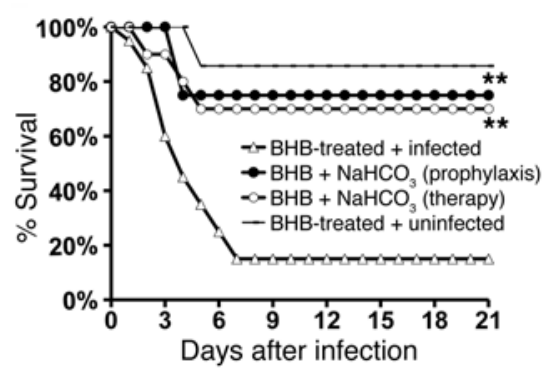

D

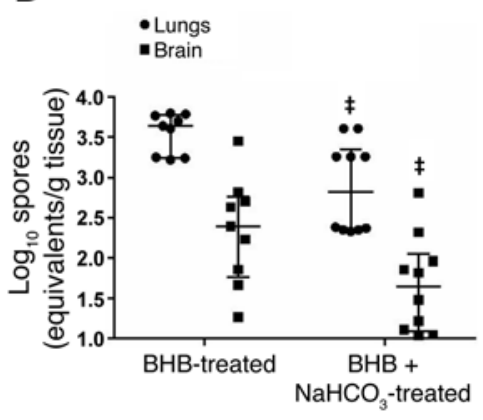

$\mathbf{F}$

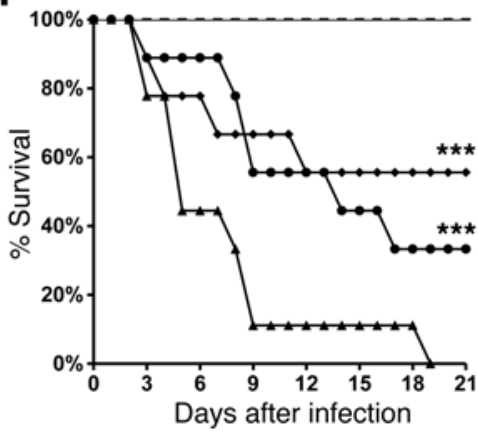

E
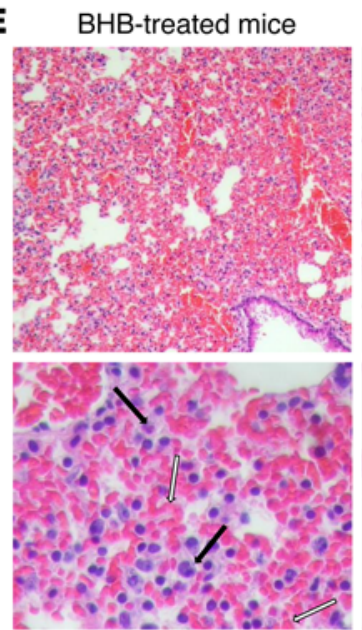

$\mathrm{NaHCO}_{3}$-treated mice
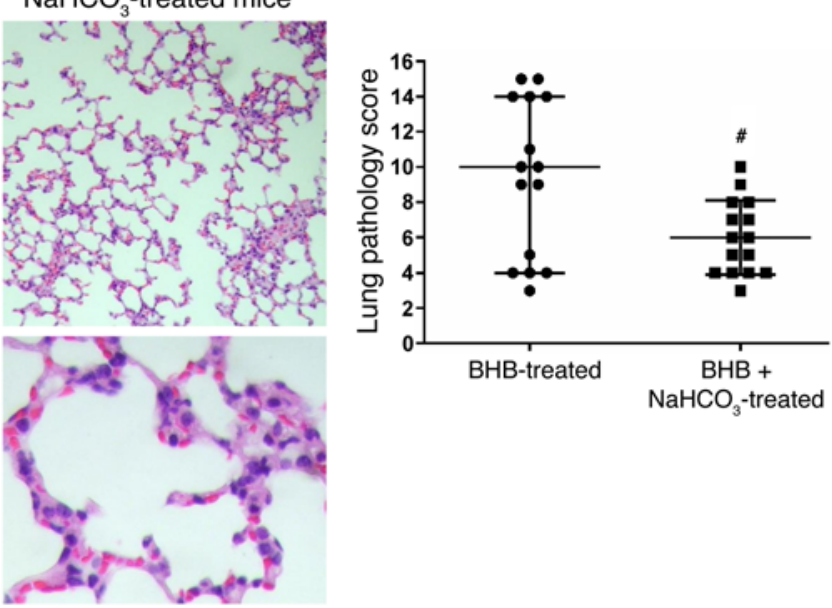

- Uninfected

-Empty plasmid strain

$\rightarrow$ RNA-i::ftr1 strain

- RNA-i::coth strain

Figure 9. $\mathrm{NaHCO}_{3}$ bicarbonate enhances survival of BHB-treated mice with mucormycosis. (A) Mice were injected 5 times with BHB ( $n=5$ per group) or BHB followed by $\mathrm{NaHCO}_{3}$ before determination of the blood $\mathrm{pH}$. (B) LPI concentrations were measured in samples collected from normal immunocompetent mice and mice treated with $\mathrm{BHB}$ or with $\mathrm{BHB}$ followed by sodium bicarbonate. Data in $\mathbf{A}$ and $\mathbf{B}$ are expressed as median \pm interquartile range. ${ }^{*} P<0.05$ vs. normal mice or $\mathrm{BHB}+\mathrm{NaHCO}_{3}$ for $\mathbf{A}$ and vs. normal mice for $\mathbf{B}$. (C) Survival of mice treated with $\mathrm{BHB}(n=20), \mathrm{BHB}+\mathrm{NaHCO}$ ( $(\mathrm{prophylaxis,}$ $n=8)$, or $\mathrm{BHB}+\mathrm{NaHCO}_{3}$ (therapy, $n=10$ ). Mice were infected with $R$. oryzae intratracheally with $2.5 \times 10^{5}$ spores (average delivered inoculum is $4.5 \times 10^{3}$ from 3 independent experiments). ${ }^{*} P=0.0085$ by log-rank test vs. BHB-treated and infected. (D) Lung and brain fungal burden of mice ( $n=10$ per group) treated with $\mathrm{BHB}$ or $\mathrm{BHB}+\mathrm{NaHCO}_{3}$ (prophylactically) was determined by qPCR 48 hours after infection. Data are expressed as median \pm interquartile range. $y$ axis value represents the lower limit of detection in the assay. ${ }^{\ddagger} P<0.04$ vs. lungs or brains from $B H B$-treated mice. (E) Histopathological images $(\mathrm{H} \& \mathrm{E})$ and cumulative score of inflammation, hemorrhage, and edema scores of lungs harvested from mice treated with $\mathrm{BHB}$ or $\mathrm{BHB}+\mathrm{NaHCO}$ (prophylactically) 48 hours after infection with $R$. oryzae, showing significantly extensive signs of pneumonia with neutrophil infiltration (black arrows) and hemorrhage (white arrows) in the lungs of mice treated with BHB. Original magnification, $\times 100$ (top); $\times 400$ (bottom). ${ }^{P}=0.04$. (F) Survival of mice ( $n=9$ per group) infected intratracheally with $R$. oryzae transformed with empty plasmid $\left(6.4 \times 10^{3}\right.$ spores) or with plasmids attenuating CotH2/CotH3 ( $4.1 \times 10^{3}$ spores) or FTR1 expression $\left(5.2 \times 10^{3}\right.$ spores). ${ }^{* *} P<0.03$ vs. mice infected with $R$. oryzae transformed with empty plasmid.

get organs and were extremely susceptible to invasive pulmonary mucormycosis, when compared with normal mice that were completely resistant to infection. Furthermore, the finding that BHB enhanced expression of CotH in vitro was mimicked by increased expression of fungal CotH in target organs recovered from BHB- treated mice compared with normal mice. The importance of GRP78/CotH interactions in BHB-treated mice is highlighted by the retarded virulence of $R$. oryzae with attenuated expression of CotH when compared with $R$. oryzae WT strain. Further, the lack of virulence of Aspergillus fumigatus in the BHB-treated mice 


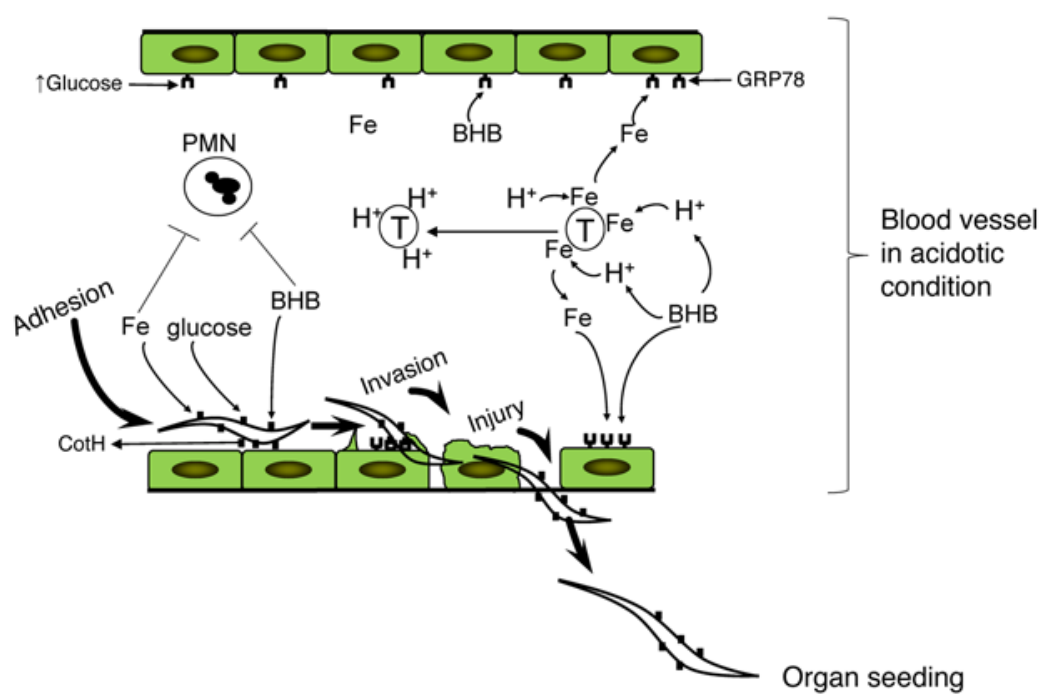

Figure 10. An illustration showing the proposed mechanism of susceptibility of the ketoacidotic host to mucormycosis. Acidosis promotes the release of iron from transferrin ( $T$ ) by protonation of the milieu. Released iron, elevated glucose, and ketone bodies (e.g., BHB) enhance the growth of the invading fungus as well as the surface expression of endothelial cell GRP78 and the fungal CotH proteins. The enhanced expression of the GRP78 receptor and its fungal ligand leads to increased invasion and subsequent injury to endothelial cells especially in the absence of neutrophil (PMN) killing of the invading fungus due to a detrimental effect exerted by iron and BHB on the phagocytes. This increased invasion results in hematogenous dissemination and organ seeding. $\mathrm{NaHCO}_{3}$ can reverse the effect of acidosis but not the direct effect of glucose, free iron, and BHB. further confirms the importance of the GRP78/CotH interactions during mucormycosis pathogenesis in this setting. It is clinically known that DKA patients are not at increased risk of contracting aspergillosis, and A. fumigatus do not bind GRP78 (5) nor do they have an ortholog to $\mathrm{Cot} H$ genes (4).

It has long been suggested that acidosis disrupts the ability of transferrin to efficiently chelate iron by a proton-mediated mechanism $(8,17)$. In fact, determination of total serum iron requires acidification of the sample to release iron from transferrin (18). Our results also support the model of disrupting the iron chelation ability of transferrin by acidosis. $\mathrm{NaHCO}_{3}$, which reversed the acidotic $\mathrm{pH}$ to neutrality, partially blocked the ability of $\mathrm{R}$. oryzae to invade endothelial cells. This partial blocking of endothelial cell invasion also occurred in the presence of the iron chelator phenanthroline. Only when $\mathrm{NaHCO}_{3}$ was combined with phenanthroline was there abrogation of the organism's ability to invade and injure endothelial cells, even to levels that were far below the notreatment control (Figure 8, B and C). Further, administration of $\mathrm{NaHCO}_{3}$ to $\mathrm{BHB}$-treated mice reversed the blood $\mathrm{pH}$ to neutrality and reduced the presence of free serum iron to levels comparable to those detected in normal mice without BHB treatment. Thus, enhancement of the disease by BHB occurred by a direct effect on the expression of both the host receptor and the fungal ligand (since these experiments were conducted in the absence of serum), as well as indirectly by a compromising of the ability of transferrin to chelate iron through acidification of the milieu. This released iron further worsened the outcome of the disease by augmenting receptor/ligand expression resulting in increased invasion of blood vessels (Figure 10). Additionally, free iron is likely to become more available to support the biological activities of the invading fungus, which leads to enhanced growth and proliferation of the infection. The release-of-iron model and its importance for the pathogenesis of mucormycosis are further supported by the decreased virulence of $R$. oryzae mutant with attenuated FTR1 expression in BHB-treated mice. It is imperative to point out that BHB might affect mechanisms independent of GRP78/CotH interactions, which in turn can affect the ability of the fungus to invade the host. For example, and as pointed out above in Figure 5A, BHB enhanced the ability of $R$. oryzae to adhere to the endothelium, a process mediated by receptors other than GRP78 and CotH $(4,5)$.

Finally, elevated free iron is known to have a profound and detrimental effect on immune cells necessary for combating mucormycosis. Specifically, elevated concentrations of iron were found to be toxic to phagocytes (19-21), and spleen cells from mice fed excess levels of iron secrete less IFN- $\gamma$ (22), a cytokine that upregulates killing of several Mucorales family members (including $R$. oryzae) by human neutrophils (23). Additionally, BHB, which has been reported to abrogate the formation of bovine neutrophil extracellular traps and their bactericidal activity against pathogen $E$. coli (9), attenuated the ability of human neutrophils to kill $R$. oryzae ex vivo by reducing ROS production. $\mathrm{NaHCO}_{3}$ restored the ability of neutrophils to kill $R$. oryzae, probably by restoring ROS production to normal levels. Thus, BHB can have pleiotropic and detrimental effects on the immune response to mucormycosis as well as directly enhancing the growth of R. oryzae (Figure 10). Because acidic conditions are known to reduce phagocyte-mediated killing mechanisms (16), the BHB attenuation of neutrophilmediated killing of $R$. oryzae is likely nonspecific.

Of potential clinical relevance is the finding that treating BHB-receiving mice with $\mathrm{NaHCO}_{3}$ protected them from infection. This protection is due, at least in part, to reversal of the enhanced fungal growth, restoration of the immune system to kill $R$. oryzae, and prevention or halting of invasion of host tissues by the fungus. Currently, diabetics with ketoacidosis are treated with glucose and insulin. The American, Canadian, and British guidelines for treatment of ketoacidosis reserve $\mathrm{NaHCO}_{3}$ treatment only for those in severe acidosis (e.g., $\mathrm{pH}<6.9)(6,24-26)$. The findings in this experimental model strongly suggest that patients with ketoacidosis plus mucormycosis may benefit by earlier treatment with $\mathrm{NaHCO}_{3}$. Also, it is important to mention that successful treatment of rhino-orbital mucormycosis, with only the reversal of acidosis by using $\mathrm{NaHCO}_{3}$ (without concomitant antifungal therapy), has been reported $(27,28)$. Furthermore, on the basis of the results of this study, it is probable that a combination of $\mathrm{NaHCO}_{3}$ plus iron chelation therapy will have either a synergistic or an additive effect in treating mucormycosis. Despite the failure of the DEFEAT study, which was mainly 


\section{Table 1. Oligonucleotides used for quantification of GRP78 or CotH expression}

\begin{tabular}{|c|c|c|}
\hline Primer name & Primer sequence & Description \\
\hline GRP78-F & GGAAAGAAGGTTACCCATGC & 5' primer (amplifying 222 bp) \\
\hline CRP78-R & AGAAGAGACACATCGAAGGT & 3' primer (amplifying 222 bp) \\
\hline CAPDH-F & ACCATCTTCCAGGAGCGAG & $5^{\prime}$ primer (amplifying 249 bp) \\
\hline CAPDH-R & TAAGCAGTTGGTGGTGCAG & 3' primer (amplifying 249 bp) \\
\hline CotH2-F & ССТAATAAGGACAACGCAAACG & 5' primer (amplifying $101 \mathrm{bp}$ ) \\
\hline Coth2-R & TTGGCAATGGCTGTGTTATC & 3' primer (amplifying 101 bp) \\
\hline CotH3-F & GCCAATCCTAATGGTCAAGC & $5^{\prime}$ primer (amplifying 126 bp) \\
\hline CotH3-R & CATCAAACGGTCGACATCAA & 3' primer (amplifying 126 bp) \\
\hline Actin-F & ACCTCCTTTCAACCСCAAGT & $5^{\prime}$ primer (amplifying 121 bp) \\
\hline Actin-R & ACGACCAGAGGCATACAAGG & 3' primer (amplifying 121 bp) \\
\hline
\end{tabular}

conducted in neutropenic, leukemic patients (29), numerous patients with DKA suffering from mucormycosis were reported to have a beneficial outcome when the iron chelator deferasirox was used in addition to other standard treatments (30).

Clearly, the concept of using $\mathrm{NaHCO}_{3}$ plus iron chelation derived from this model needs validation in patient trials. However, the complexities of the study design, extensive funding, and multiple years required make it unlikely such a study will ever be performed.

In summary, our results provide a model that explains the unique susceptibility of patients with DKA to mucormycosis. In this model, host factors such as uncontrolled blood glucose and acidotic conditions due to ketone bodies (e.g., BHB) lower the ability of transferrin to chelate iron. The elevated free iron, glucose, and BHB enhance the growth of the fungus, attenuate host defense mechanisms, and augment the expression of host GRP78 and its fungal $\mathrm{CotH}$, which result in increased hematogenous dissemination of the disease (Figure 10). This model could be also operative in mucormycosis cases seen in patients with severe trauma and myonecrosis, since metabolic processes of acidosis, and stress hyperglycemia, produce the same conducive environment, albeit with a mechanism that does not include a direct effect on GRP78/CotH expression. Novel strategies that target early reversal of acidosis with $\mathrm{NaHCO}_{3}$ combined with iron chelation and/ or blocking strategies of GRP78/CotH interaction (e.g., blocking antibodies; refs. 4,5 ) are likely to augment current treatment options against lethal mucormycosis. Since Mucorales other than R. oryzae bind GRP78 (5), and CotH genes are universally present among fungi belonging to this order (4), our observations are likely to extend to other Mucorales-causing organisms. It remains to be determined, however, whether GRP78 and CotH play a role in other susceptible hosts (e.g., neutropenic patients) or in the initiation of infection. Also, other aspects of the disease pathogenesis in the DKA host remain unclear. For example, it is clinically established that DKA patients are almost exclusively susceptible to rhino-orbital-cerebral mucormycosis, while patients in the setting of iatrogenic immunosuppression mainly develop pulmonary infection. Our results show that BHB-treated mice had increased expression of GRP78 in all target organs, including sinus, lungs, and brain. Thus, the GRP78/CotH interactions cannot explain the enhanced susceptibility of DKA hosts to the rhinocerebral form of mucormycosis. It is likely that environmental factors seen in DKA patients (i.e., hyperglycemia, elevated iron and BHB) have effects on tissue-specific host-pathogen interactions that are independent of GRP78 and CotH. These and related topics are active areas of investigation in our laboratory.

\section{Methods}

Organisms and culture conditions. R. oryzae $99-880$ is a brain isolate obtained from the University of Texas Health Science Center at San Antonio, which had its genome sequenced (31). The organism was grown on potato dextrose agar (PDA; BD Diagnostic) plates for 5-7 days at $37^{\circ} \mathrm{C}$. The sporangiospores were collected in endotoxin-free Dulbecco's PBS containing 0.01\% Tween-80, washed with PBS, and counted with a hemocytometer to prepare the final inocula. To form germlings, spores were incubated in liquid Minimum Essential Medium (MEM; Mediatech) at $37^{\circ} \mathrm{C}$ with shaking for 3 hours. Germlings were washed twice with MEM.

Endothelial cells. Endothelial cells were collected from umbilical vein endothelial cells by the method of Jaffe et al. (32). Secondpassage cells were grown to confluence in 24- or 96-well tissue culture plates (Costar) on fibronectin (BD Biosciences). All incubations were in $5 \% \mathrm{CO}_{2}$ at $37^{\circ} \mathrm{C}$. The reagents were tested for endotoxin using a chromogenic limulus amebocyte lysate assay (BioWhittaker Inc.), and the endotoxin concentrations were less than $0.01 \mathrm{IU} / \mathrm{ml}$.

Quantification of GRP78 and CotH gene expression. To quantify the expression of GRP78 in endothelial cells or $\mathrm{CotH}$ genes in fungal cells, real-time RT-PCR was carried out using a Power SYBR Green Cells-to-CT kit (Applied Biosystems). RNA was extracted from flashfrozen cells (starting cells of $2 \times 10^{4}$ endothelial cells or $5 \times 10^{5}$ spores) after incubating with the stimulus for the specified time period using RNeasy Plant Mini Kit (Qiagen). Reverse transcription was performed with RETROscript (Ambion). For quantitative RT-PCR, SYBR green assays were performed using primers listed in Table 1 . The housekeeping genes of GAPDH for endothelial cells and ACT1 for the fungal cells were used as controls for all reactions. Calculations and statistical analyses were performed using StepOne Real-Time PCR System (Applied Biosystems).

Cell surface localization of GRP78 and CotH proteins. Cell surface expression of GRP78 on endothelial cells or CotH proteins on R. oryzae exposed to varying concentrations of $\mathrm{FeCl}_{3}$, glucose, or $\mathrm{BHB}$ with or without $\mathrm{NaHCO}_{3}$ was quantified using FACS analysis. Briefly, endothelial cells grown in 25-cm flasks were dissociated using $1.5 \mathrm{ml}$ enzyme-free dissociation buffer (Invitrogen). Cells were blocked with $50 \%$ goat serum, then stained with monoclonal anti-GRP78 antibody (catalog 610979; BD Biosciences) at 1:100 for 1 hour. Endothelial cells were counterstained with Alexa Fluor 488-labeled anti-mouse IgG (catalog A-11001; Life Technologies) at 1:100 for 1 hour. Endothelial cells exposed to a similar concentration of the stimulus and stained with an isotype matching control IgG (catalog 554126; BD Biosciences) were used as negative control. For CotH expression on fungal cells, $R$. oryzae spores $\left(3 \times 10^{6}\right.$ spores $\left./ \mathrm{ml}\right)$ were germinated in MEM with or without $\mathrm{FeCl}_{3}$, glucose, $\mathrm{BHB}$ with or without $\mathrm{NaHCO}_{3}$, lactic acid, or $\mathrm{HCl}$ for 3 hours at $37^{\circ} \mathrm{C}$. Lactic acid and $\mathrm{HCl}$ were added at concentrations to lower the $\mathrm{pH}$ of the medium to 6.8 , which is equivalent to a $\mathrm{pH}$ drop caused by $10 \mathrm{mM}$ BHB. Germlings $\left(10^{5}\right.$ cells $\left./ \mathrm{ml}\right)$ were incubated with the anti-CotH purified polyclonal IgG (4) at 1:100 for 
1 hour on ice after a blocking step using $1.5 \%$ goat serum in PBS for 1 hour. The cells were washed 3 times with tris-buffered saline (TBS; $0.01 \mathrm{M}$ Tris $\mathrm{HCl}$ [pH 7.4], $0.15 \mathrm{M} \mathrm{NaCl}$ ) containing 0.05\% Tween-20, then counterstained with Alexa Fluor 488-labeled goat anti-rabbit IgG (catalog A11034; Life Technologies) at 1:100 for 1 hour on ice. Germlings exposed to the same conditions and stained with preimmune IgG from the same rabbit were used as negative control. One-milliliter samples from either endothelial cells or R. oryzae germlings were analyzed using a FACSCalibur (Becton Dickinson) instrument equipped with an argon laser emitting at $488 \mathrm{~nm}$. Fluorescence emission was read with a 515/40 bandpass filter. Fluorescence data were collected with logarithmic amplifiers. The mean fluorescence intensities of $10^{4}$ events were calculated using CellQuest software (33).

Interactions of fungi with endothelial cells. The number of organisms endocytosed by endothelial cells was determined using our previously described differential fluorescence assay $(6,7)$. R. oryzae $\left(10^{5}\right.$ cells) that had been germinated for 1 hour were added to endothelial cells grown on 12-mm glass coverslips in the presence or absence of the stimuli (i.e., $\mathrm{FeCl}_{3}$, glucose, or $\mathrm{BHB}$ [with or without $\mathrm{NaHCO}_{3}$ ]). Following incubation for 2 hours, the cells were fixed, stained with $1 \%$ Uvitex (Polysciences) for 1 hour, and examined using phase-contrast microscopy, and the total number of cell-associated organisms (i.e., germlings adhering to monolayer) was enumerated $(6,7)$. The same field was examined by epifluorescence microscopy, and the number of uninternalized germlings (which were brightly fluorescent) was determined. The number of endocytosed organisms was calculated by subtraction of the number of fluorescent organisms from the total number of visible organisms. At least 400 organisms were counted in 20-40 different fields on each slide.

$R$. oryzae-induced endothelial cell damage was quantified using a chromium $\left({ }^{51} \mathrm{Cr}\right)$ release assay after a 4 -hour incubation period of the fungus with endothelial cells cultured in 96-well plates (34). To study the effect of iron, glucose, or BHB on R. oryzae CotH expression level and subsequent interactions of endothelial cells with $R$. oryzae, we germinated $R$. oryzae cells in MEM with $\mathrm{FeCl}_{3}$, glucose, or BHB for 1 hour at $37^{\circ} \mathrm{C}$. Conversely, to study the effect of iron, glucose, or $\mathrm{BHB}$ on the host, endothelial cells were incubated in MEM without glutamate and supplemented with $\mathrm{FeCl}_{3}$, glucose, or $\mathrm{BHB}$ for 1 hour at $37^{\circ} \mathrm{C}$ in a $5 \% \mathrm{CO}_{2}$ incubator (5). Endocytosis and damage assays were conducted as above.

To investigate whether $\mathrm{NaHCO}_{3}$ and phenanthroline reversed the effect of BHB on R. oryzae interacting with endothelial cells, endothelial cells or R. oryzae spores were incubated in MEM containing $50 \%$ FBS supplemented with BHB (10 mM), BHB with $\mathrm{NaHCO}_{3}(26 \mathrm{mM})$, BHB with phenanthroline $(30 \mu \mathrm{M})$, or BHB with $\mathrm{NaHCO}_{3}$ and phenanthroline for 1 hour at $37^{\circ} \mathrm{C}$ before being introduced in the interaction assay as above.

Growth studies. To investigate the effect of $\mathrm{BHB}$ and $\mathrm{NaHCO}_{3}$ on the growth of $R$. oryzae, RPMI-1640 without phenol red media was inoculated with $5 \times 10^{5}$ spores per milliliter. The medium contained $10 \%$ FBS (Gemini Bioproducts) and was supplemented with $10 \mathrm{mM} \mathrm{BHB}, 26 \mathrm{mM}$ $\mathrm{NaHCO}_{3}$, or both. The $\mathrm{pH}$ of the inoculated media was measured with a $\mathrm{pH}$ meter before they were incubated at $37^{\circ} \mathrm{C}$ with shaking. At different time intervals, a 1-ml sample was taken from the culture and the absorbance was measured at $600 \mathrm{~nm}$ spectrophotometrically.

In other studies, freshly collected $R$. oryzae spores $\left(10^{5}\right.$ in $\left.10 \mu \mathrm{l}\right)$ were plated in the middle of agar plates of RPMI-1640 without phe- nol red and with 10\% FBS supplemented with $10 \mathrm{mM} \mathrm{BHB}, 26 \mathrm{mM}$ $\mathrm{NaHCO}_{3}$, or both. The plates were left to dry at room temperature before incubation at $37^{\circ} \mathrm{C}$ for 24 hours when the diameter of the colony was measured in centimeters.

Neutrophil inhibition assay. Blood samples were collected from volunteers after an IRB approved consent form was obtained, and neutrophils were purified as described before (35). Neutrophils $\left(2.0 \times 10^{4}\right.$ in HBSS containing $10 \%$ serum) were incubated with $10 \mathrm{mM} \mathrm{BHB}$ or BHB $+26 \mathrm{mM} \mathrm{NaHCO}_{3}$ for 1.5 hours in a 96 -well tissue culture plate at $37^{\circ} \mathrm{C}$ in $5 \% \mathrm{CO}_{2}$. $R$. oryzae were added to each well to achieve a ratio of 1:10 of $R$. oryzae spores to neutrophils. The 96 -well plate was further incubated at $37^{\circ} \mathrm{C}$ in a $5 \% \mathrm{CO}_{2}$ incubator for 2 hours, after which the plate was refrigerated overnight to kill all neutrophils. The next morning, 40 $\mu \mathrm{l}$ of $1 \mathrm{mg} / \mathrm{ml} \mathrm{XTT} \mathrm{(Sigma-Aldrich)} \mathrm{and} 2 \mu \mathrm{l}$ of $0.625 \mathrm{mM}$ menadione solution (Sigma-Aldrich) were added to the 96-well plates to allow the conversion of the XTT to its formazan derivative. The plate was shaken for 1-2 minutes at $100 \mathrm{rpm}$ using a microtiter plate reader until complete dissolution of the formazan derivatives. The plate was incubated at $37^{\circ} \mathrm{C}$ for an additional 6 hours before the XTT conversion was measured using DYNEX MRX Revelation microtiter plate reader (BioSurplus) at an OD of $450 \mathrm{~nm}$. XTT conversion by metabolically active cells was calculated after subtraction of the background OD of simultaneously incubated wells containing media and reagents without spores.

ROS determination. To study the effect of $\mathrm{BHB}$ or $\mathrm{BHB}+\mathrm{NaHCO}_{3}$ on the ability of neutrophils to produce ROS, we incubated $1.7 \times 10^{5}$ neutrophils in $500 \mu \mathrm{l} \mathrm{HBSS}$ with $10 \mathrm{mM} \mathrm{BHB}$ or $\mathrm{BHB}+26 \mathrm{mM} \mathrm{NaHCO}_{3}$ for 1.5 hours at $37^{\circ} \mathrm{C}$ in a $5 \% \mathrm{CO}_{2}$ incubator. Neutrophils without any added $\mathrm{BHB}$ or $\mathrm{NaHCO}_{3}$ were used as a control. At the end of the incubation period, $1 \mu \mathrm{g} / \mathrm{ml}$ of phorbol 12-myristate 13-acetate (PMA; SigmaAldrich) and $100 \mu \mathrm{M}$ of DHR123 (Molecular Probes) were added to all wells and incubated in the dark for 25 minutes at $37^{\circ} \mathrm{C}$ in $5 \% \mathrm{CO}_{2}$. Within 30 minutes from addition of DHR123 dye, the samples were analyzed for size and fluorescence using a FACSCalibur instrument (Becton Dickinson) as above (33).

In vivo virulence studies. Male ICR mice ( $\geq 20 \mathrm{~g}$ ) were purchased from Taconic and housed in groups of 5 . They were given irradiated feed and sterile water. To study the effect of BHB on susceptibility of mice to R. oryzae infection, normal mice were injected with $5 \mathrm{mg}$ BHB every 2 hours for a total of 5 doses administered by i.p. injection (36), after which a blood sample was analyzed for $\mathrm{pH}$ levels (VetScan i-STAT 1 analyzer, CG4+ Cartridge; Abaxis Inc.) and serum BHB concentrations using a BHB Assay kit (Sigma-Aldrich). Additionally, target organs (lungs, brain, and sinus) were collected from BHB-treated mice and processed for comparing Grp78 expression with that of normal mice as previously described (5). We also studied the effect of $\mathrm{NaHCO}_{3}$ on reversing the effect of BHB in mice. Briefly, normal mice were injected with $\mathrm{BHB}$ as above plus $200 \mathrm{mM} \mathrm{NaHCO}_{3}(37)$, after which the $\mathrm{pH}$ of the blood was determined. Mice with induced or reversed ketoacidosis were infected intratracheally with fungal spores $\left(2.5 \times 10^{5}\right)$ after the fifth dose of $\mathrm{BHB}$ or $\mathrm{BHB}+\mathrm{NaHCO}_{3}$ (prophylactic treatment) following sedation (4). Two additional doses of BHB or $\mathrm{BHB}+\mathrm{NaHCO}_{3}$ were given 24 and 48 hours after infection. In another experiment, $\mathrm{NaHCO}_{3}$ was initiated only on days 1 and 2 after infection and given concurrently with BHB (therapy).

To evaluate the role of $\operatorname{CotH}$ or FTR1 in the pathogenesis of mucormycosis in the BHB-treated animals, mice were treated with $\mathrm{BHB}$ as above before being infected intratracheally with $R$. oryzae 
mutants with attenuated expression of $\operatorname{CotH} 2 / \operatorname{CotH} 3$ or FTR1, or $R$. oryzae transformed with empty plasmid (control strain behaving like WT strain) $(4,13)$.

The primary efficacy end point was time to moribundity. In some experiments, fungal burden in the lungs and brains using qPCR as well as histopathological examination with $\mathrm{H} \& \mathrm{E}$ stain was determined 48 hours after infection $(4,33)$. Values were expressed as $\log _{10}$ spore equivalents per gram tissue. Cumulative histopathological scores of hemorrhage, neutrophil infiltration (inflammation), and edema were used to semiquantify signs of pneumonia due to BHB or $\mathrm{BHB}+\mathrm{NaHCO}_{3}$ treatment in 3 mice per arm by looking into 5 fields per slide by a blinded examiner.

Expression of $\mathrm{Cot} H$ genes in the lungs and brains harvested from mice 48 hours after infection was quantified by RT-PCR using primers listed in Table 1 and ref. 4 . Constitutively expressed ACT1 was used as a control for all reactions. Calculations and statistical analyses were performed using StepOne Real-Time PCR System (Applied Biosystems).

We also determined the susceptibility of BHB-treated mice to $A$. fumigatus. BHB-treated mice (as above) were infected with $A$. fumigatus (strain AF293) via inhalation (10). The susceptibility of the BHB-treated mice to aspergillosis was compared with that of mice immunosuppressed by cyclophosphamide $(200 \mathrm{mg} / \mathrm{kg})$ and cortisone acetate $(250$ $\mathrm{mg} / \mathrm{kg}$ ) administered on days $-2,+3$, and +8 , relative to infection (10).

Measurement of mouse labile plasma iron. To study the effect of $\mathrm{BHB}$ and $\mathrm{NaHCO}_{3}$ on the release of iron from transferrin (named labile plasma iron [LPI], which is redox active and chelatable), we used the method developed by Esposito et al. (38). Briefly, mice were treated with 5 doses of $\mathrm{BHB}$ as above. In a separate group of mice, $\mathrm{NaHCO}_{3}$ $(200 \mathrm{mM})$ was given to mice after the last dose of BHB as above. Mice were euthanized 1 hour following the last dose of $\mathrm{BHB}+\mathrm{NaHCO}_{3}$ and serum separated from whole blood. Quadruplicates of $20-\mu \mathrm{l}$ serum samples collected from immunocompetent, BHB-treated, or BHB $+\mathrm{NaHCO}_{3}$-treated mice were transferred to 96-well plates. To 2 of the serum samples, $180 \mu \mathrm{l}$ of iron-free HEPES-buffered saline (HBS; HEPES $20 \mathrm{mM}, \mathrm{NaCl} 150 \mathrm{mM}, \mathrm{pH}$ 7.4, treated with $1 \mathrm{~g}$ per $100 \mathrm{ml}$ Celax-100 chelating resin [Bio-Rad]) containing $40 \mu \mathrm{M}$ ascorbate and $50 \mu \mathrm{M}$ dihydrorhodamine 123 dihydrochloride salt (DHR123; Biotium) was added. To the other 2 wells, $180 \mu \mathrm{l}$ of the same solution containing $50 \mu \mathrm{M}$ deferoxamine mesylate salt (Sigma-Aldrich) was added. Next, the kinetics of fluorescence increase was followed at $37^{\circ} \mathrm{C}$ in a Synergy 2 Multi-Mode Reader (BioTek) with a 485/538 excitation/emission filter for 40 minutes, with readings taken every 2 minutes. The slopes $(r)$ of DHR123 fluorescence intensity with time were calculated from measurements taken between 16 and 40 minutes. Duplicate values of $r$ in the presence and absence of deferoxamine (i.e., $r_{D E F}$ and $r$, respectively) were averaged, and the LPI concentration $(\mu \mathrm{M})$ was calculated from a calibration curve indicating the difference in slopes with and without deferoxamine against known concentrations of $\mathrm{Fe}^{3+}$ using an $\mathrm{Fe}^{3+} /$ nitrilotriacetic acid complex with 1:7 ratio $\left(r_{s t}\right)$. LPI values were calculated from the following equation: LPI $=\Delta r / r_{\mathrm{st}}=\left(r-r_{\mathrm{DEF}}\right) / r_{\mathrm{st}}$, where $\Delta r$ and $r_{\mathrm{st}}$ denote the deferoxamine-sensitive component of $r$ and the calibration factor relating $\Delta r$ to the $\mathrm{Fe}^{3+}$ concentration, respectively.

Statistics. Differences in GRP78 or CotH expression, fungus-endothelial cell interactions, and tissue fungal burden were compared by the nonparametric Wilcoxon rank sum test or with 2-tailed $t$ test for unpaired comparison. The nonparametric log-rank test was used to determine differences in survival times. For all comparisons, a $P$ value less than 0.05 was considered significant.

Study approval. Animal studies were approved by the IACUC of the Los Angeles Biomedical Research Institute at Harbor-UCLA Medical Center, according to the NIH guidelines for animal housing and care. Human endothelial cell collection was approved by the IRB at the Los Angeles Biomedical Research Institute at HarborUCLA Medical Center.

\section{Author contributions}

JEE, SGF, and ASI conceived and designed the experiments. TG, LL, ML, DPK, and ASI performed the experiments. TG, SF, and ASI analyzed the data. TG and ASI wrote the paper. DPK, JEE, and SGF revised the paper.

\section{Acknowledgments}

This work was supported by Public Health Service grants R01 AI063503 and 1R41 AI115907-01 to A.S. Ibrahim. Collection of human umbilical cord endothelial cells was supported by grant UL1TR000124. S.G. Filler and J.E. Edwards Jr. are supported by grants R01 AI054928 and R01 AI063382, respectively. We acknowledge the technical assistance of the perinatal nurses of the Harbor-UCLA Medical Center for collection of umbilical cords. Research described in this article was conducted at the research facilities of the Los Angeles Biomedical Research Institute at Harbor-UCLA Medical Center.

Address correspondence to: Ashraf S. Ibrahim, Los Angeles Biomedical Research Institute, Division of Infectious Diseases, Harbor-UCLA Medical Center, 1124 West Carson Street, St. John's Cardiovascular Research Center, Torrance, California 90502, USA. Phone: 310.222.6424; E-mail: ibrahim@labiomed.org.

This work was presented in part at the 24th European Congress of Clinical Microbiology and Infectious Diseases in Barcelona, Spain, in May 2014 (P0026), and at the 54th Interscience Conference on Antimicrobial Agents and Chemotherapy in Washington, DC, September 5-9, 2014 (abstract M-1276).
1. Sugar AM. Agents of mucomycosis and related species. In: Mandell GL, Bennett JE, Dolin R, eds. Principles and Practice of Infectious Diseases. Vol. 2. 6th ed. Philadelphia, PA, USA: Elsevier Churchill Livingstone; 2005:2973-2984.

2. Ibrahim AS, Edwards JE Jr, Filler SG, Spellberg B. Mucormycosis and Entomophthoramycosis (Zygomycosis). In: Kauffman CA, Pappas PP, Sobel JD, Dismukes WE, eds. Essentials of Clinical Mycology. 2nd ed. New York, New York, USA:
Springer; 2011:265-280.

3. Ibrahim AS, Spellberg B, Avanessian V, Fu Y, Edwards JE Jr. Rhizopus oryzae adheres to, is phagocytosed by, and damages endothelial cells in vitro. Infect Immun. 2005;73(2):778-783.

4. Gebremariam T, et al. CotH3 mediates fungal invasion of host cells during mucormycosis. J Clin Invest. 2014;124(1):237-250.

5. Liu M, et al. The endothelial cell receptor GRP78 is required for mucormycosis pathogenesis in dia- betic mice. J Clin Invest. 2010;120(6):1914-1924.

6. UpToDate. www.uptodate.com. Accessed April 6, 2016.

7. Fulop M, Hoberman HD, Rascoff JH, Bonheim NA, Dreyer NP, Tannenbaum H. Lactic acidosis in diabetic patients. Arch Intern Med. 1976;136(9):987-990.

8. Artis WM, Fountain JA, Delcher HK, Jones HE. A mechanism of susceptibility to mucormycosis in diabetic ketoacidosis: transferrin and iron avail- 
ability. Diabetes. 1982;31(12):1109-1114.

9. Grinberg N, Elazar S, Rosenshine I, Shpigel NY. Beta-hydroxybutyrate abrogates formation of bovine neutrophil extracellular traps and bactericidal activity against mammary pathogenic Escherichia coli. Infect Immun. 2008;76(6):2802-2807.

10. Sheppard DC, Rieg G, Chiang LY, Filler SG, Edwards JE Jr. Ibrahim AS. Novel inhalational murine model of invasive pulmonary aspergillosis. Antimicrob Agents Chemother. 2004;48(5):1908-1911.

11. Im MS, Ahn HS, Cho HJ, Kim KB, Lee HY. Diabetic ketoacidosis associated with acute pancreatitis in a heart transplant recipient treated with tacrolimus. Exp Clin Transplant. 2013;11(1):72-74.

12. Di Iorio B, Aucella F, Conte G, Cupisti A, Santoro D. A prospective, multicenter, randomized, controlled study: the correction of metabolic acidosis with use of bicarbonate in Chronic Renal Insufficiency (UBI) Study. J Nephrol. 2012;25(3):437-440.

13. Ibrahim AS, et al. The high affinity iron permease is a key virulence factor required for Rhizopus oryzae pathogenesis. Mol Microbiol. 2010;77(3):587-604.

14. Oswal NP, Gadre PK, Sathe P, Gadre KS. Mucormycosis of mandible with unfavorable outcome. Case Rep Dent. 2012;2012:257940.

15. Imbernon A, et al. Successful therapy of progressive rhino-orbital mucormycosis caused by Rhizopus arrhizus with combined and sequential antifungal therapy, surgery and hyperbaric therapy. Med Mycol Case Rep. 2014;6:51-54.

16. Lardner A. The effects of extracellular $\mathrm{pH}$ on immune function. J Leukoc Biol. 2001; 69(4):522-530.

17. Ibrahim AS, Spellberg B, Edwards J Jr. Iron acquisition: a novel perspective on mucormycosis pathogenesis and treatment. Curr Opin Infect Dis. 2008;21(6):620-625.

18. Marsili G, Tacconi R, Cipriani S. Determination of serum iron and the total iron-binding capacity with a new chromogen, 4-aminophenazone. Ric Clin Lab. 1980;10(2):423-429.

19. Cantinieaux B, et al. Ferritin-associated iron induces neutrophil dysfunction in hemosiderosis. J Lab Clin Med. 1999;133(4):353-361.

20. Guo D, et al. Impact of iron dextran on polymorphonuclear cell function among hemodialysis patients. Clin Nephrol. 2002;58(2):134-142.

21. Omara FO, Blakley BR, Huang HS. Effect of iron status on endotoxin-induced mortality, phagocytosis and interleukin-1 alpha and tumor necrosis factor-alpha production. Vet Hum Toxicol. 1994;36(5):423-428.

22. Omara FO, Blakley BR. The effects of iron deficiency and iron overload on cell-mediated immunity in the mouse. Br J Nutr. 1994;72(6):899-909.

23. Gil-Lamaignere C, Simitsopoulou M, Roilides E, Maloukou A, Winn RM, Walsh TJ. Interferon- $\gamma$ and granulocyte-macrophage colony-stimulating factor augment the activity of polymorphonuclear leukocytes against medically important zygomycetes. J Infect Dis. 2005;191(7):1180-1187.

24. Savage MW, et al. Joint British Diabetes Societies guideline for the management of diabetic ketoacidosis. Diabet Med. 2011;28(5):508-515.

25. Skitch SA, Valani R. Treatment of pediatric diabetic ketoacidosis in Canada: a review of treatment protocols from Canadian pediatric emergency departments. CJEM. 2015;17(6):656-661.

26. Westerberg DP. Diabetic ketoacidosis: evaluation and treatment. Am Fam Physician. 2013;87(5):337-346.

27. Roden MM, et al. Epidemiology and outcome of zygomycosis: a review of 929 reported cases. Clin Infect Dis. 2005;41(5):634-653.

28. Abraham P, Govil S, Srivastava VM, Ganesh A. Spontaneous regression of pulmonary mucormycosis. Postgrad Med J. 1995;71(840):632-634.

29. Spellberg B, et al. The Deferasirox-AmBisome
Therapy for Mucormycosis (DEFEAT Mucor) study: a randomized, double-blinded, placebocontrolled trial. J Antimicrob Chemother. 2012;67(3):715-722.

30. Spellberg B, et al. Safety and outcomes of openlabel deferasirox iron chelation therapy for mucormycosis. Antimicrob Agents Chemother. 2009;53(7):3122-3125.

31. Ma LJ, et al. Genomic analysis of the basal lineage fungus Rhizopus oryzae reveals a whole-genome duplication. PLoS Genet. 2009;5(7):e1000549.

32. Jaffe EA, Nachman RL, Becker CG, Minick CR. Culture of human endothelial cells derived from umbilical veins. Identification by morphologic and immunologic criteria. J Clin Invest. 1973;52(11):2745-2756.

33. Ibrahim AS, et al. The iron chelator deferasirox protects mice from mucormycosis through iron starvation. JClin Invest. 2007;117(9):2649-2657.

34. Ibrahim AS, et al. Bacterial endosymbiosis is widely present among zygomycetes but does not contribute to the pathogenesis of mucormycosis JInfect Dis. 2008;198(7):1083-1090.

35. Tsuchimori N, Sharkey LL, Fonzi WA, French SW, Edwards JE Jr, Filler SG. Reduced virulence of HWP1-deficient mutants of Candida albicans and their interactions with host cells. Infect Immun. 2000;68(4):1997-2002.

36. Eiger SM, Kirsch JR, D'Alecy LG. Hypoxic tolerance enhanced by $\beta$-hydroxybutyrate-glucagon in the mouse. Stroke. 1980;11(5):513-517.

37. Robey IF, Martin NK. Bicarbonate and dichloroacetate: evaluating $\mathrm{pH}$ altering therapies in a mouse model for metastatic breast cancer. $B M C$ Cancer. 2011;11:235.

38. Esposito BP, Breuer W, Sirankapracha P, Pootrakul P, Hershko C, Cabantchik ZI. Labile plasma iron in iron overload: redox activity and susceptibility to chelation. Blood. 2003;102(7):2670-2677. 